Article

\title{
On the Design of Power Law Filters and Their Inverse Counterparts
}

\author{
Shibendu Mahata ${ }^{1}$ (D), Norbert Herencsar ${ }^{2, *(D)}$ and David Kubanek ${ }^{2}$ (D) \\ 1 Department of Electrical Engineering, Dr. B. C. Roy Engineering College, Durgapur 713206, PO, India; \\ shibendu.mahata@bcrec.ac.in \\ 2 Department of Telecommunications, Faculty of Electrical Engineering and Communication, Brno University \\ of Technology, Technicka 12, 61600 Brno, Czech Republic; kubanek@vutbr.cz \\ * Correspondence: herencsn@ieee.org; Tel.: +420-541-146-981
}

Citation: Mahata, S.; Herencsar, N.; Kubanek, D. On the Design of Power Law Filters and Their Inverse Counterparts. Fractal Fract. 2021, 5 , 197. https://doi.org/10.3390/ fractalfract5040197

Academic Editor: Ricardo Almeida

Received: 21 September 2021

Accepted: 1 November 2021

Published: 4 November 2021

Publisher's Note: MDPI stays neutral with regard to jurisdictional claims in published maps and institutional affiliations.

Copyright: (c) 2021 by the authors. Licensee MDPI, Basel, Switzerland. This article is an open access article distributed under the terms and conditions of the Creative Commons Attribution (CC BY) license (https:// creativecommons.org/licenses/by/ $4.0 /)$.
Abstract: This paper presents the optimal modeling of Power Law Filters (PLFs) with the lowpass (LP), high-pass (HP), band-pass (BP), and band-stop (BS) responses by means of rational approximants. The optimization is performed for three different objective functions and secondorder filter mother functions. The formulated design constraints help avoid placement of the zeros and poles on the right-half s-plane, thus, yielding stable PLF and inverse PLF (IPLF) models. The performances of the approximants exhibiting the fractional-step magnitude and phase responses are evaluated using various statistical indices. At the cost of higher computational complexity, the proposed approach achieved improved accuracy with guaranteed stability when compared to the published literature. The four types of optimal PLFs and IPLFs with an exponent $\alpha$ of 0.5 are implemented using the follow-the-leader feedback topology employing AD844AN current feedback operational amplifiers. The experimental results demonstrate that the Total Harmonic Distortion achieved for all the practical PLF and IPLF circuits was equal or lower than $0.21 \%$, whereas the Spurious-Free Dynamic Range also exceeded 57.23 and 54.72 dBc, respectively.

Keywords: analog filter approximation; analog signal processing; fractional-order filter; inverse filter

\section{Introduction}

The theoretical concepts of fractional calculus [1-3], which generalized differ-integral operators, have led to significant developments in circuit theory, signal processing, control theory, bio-impedance modeling, etc. [4-8]. Fractional-order (FO) filters are considered as the generalization of the traditional filters [9]. This is due to the ability of the FO filters to achieve any roll-off rate [10]; in contrast, an integer-order filter can only achieve a rolloff at $-20 \log _{10} n$ decibels / decade $(\mathrm{dB} / \mathrm{dec})$, where $n$ is an integer [11]. FO analog filter transfer functions are generally realized from the integer-order filters by substitution of the Laplacian operator $s$ with the non-integer Laplacian operator $s^{\alpha}$, where $\alpha \in(0,1)$. The frequency-domain transfer function of $s^{\alpha}$ is given by (1):

$$
(j \omega)^{\alpha}=\omega^{\alpha}\left[\cos \left(\frac{\alpha \pi}{2}\right)+j \sin \left(\frac{\alpha \pi}{2}\right)\right],
$$

where $j=\sqrt{-1}$ and $\omega$ is the angular frequency in radians per second ( $\mathrm{rad} / \mathrm{s})$.

Since $s^{\alpha}$ is an irrational function, various rational approximations based on series truncation, frequency-domain curve-fitting, pole-zero placement, optimization techniques, etc., have been reported [12-15]. The impedance characteristics of the operator $s^{\alpha}$ may be practically realized using the FO elements (also known as the fractance devices or the constant phase elements) [16-18]. Due to the unavailability of the commercial FO device, their behavior may be emulated using the passive and active circuits [19-22].

Recent works have demonstrated the generalization of the Butterworth [23], Chebyshev [24], inverse Chebyshev [25], and elliptic filters [26] to the FO domain. Another design 
strategy that involves the approximation of FO filter characteristics using the integer order transfer function was also reported in the literature [27]. The integer order approximant can be realized using the field programmable analog array [28], voltage mode operational amplifier [29], switched capacitor [30], operational transconductance amplifier (OTA) [31], and current feedback operational amplifier (CFOA) [32].

The application of numerical and metaheuristic optimization algorithms for the approximation of FO filters has gained traction in recent years. The modeling of FO RLC filter and low-pass filter transfer functions of the form $1 /(s+1)^{\alpha}$ using classical optimization techniques has been reported [33,34]. Numerical optimization methods were employed for the approximation of low-pass [35,36] and band-pass [37,38] filters exhibiting fractional-step behavior. The Nelder-Mead simplex [39], Cuckoo Search algorithm [40], and MATLAB-based optimization function fmincon [41,42] were employed to model the magnitude-frequency characteristics of the FO low-pass Butterworth filter. The performances of several nature-inspired algorithms were compared for the optimal rational approximation of the $s^{\alpha}$ operator [43]. The optimal design of a grounded FO inductor based on the generalized impedance converter was reported in [44]. $(1+\alpha)$ and $(\alpha+\beta)$ order, where $\alpha, \beta \in(0,1)$, low-pass Bessel filter characteristics were optimally approximated using the Interior Search algorithm [45].

Since inverse filters yield the reciprocal frequency characteristic of the system that causes distortion during transmission or reception, these filters are widely used in communication systems to alleviate signal distortion [46]. Inverse filters are also employed in acoustic systems [47], proportional integral derivative controllers [48], and digital filtering [49]. Realizations of FO inverse filters using the operational amplifiers [50], CFOAs [51], operational trans-resistance amplifiers [52], and OTAs [53] have been recently reported.

A new class of FO filters, namely the Power Law Filter (PLF), was approximated based on a frequency-domain curve fitting using the Sanathanan-Koerner (S-K) leastsquare iterative method in [54]. Applications of power law compensators and filters in achieving robust frequency compensation of process plants with uncertainties [55] and in bio-impedance modeling of fruits [56] have also been exemplified. The transfer function, magnitude-frequency, and phase-frequency relationships for these filters exhibiting the low-pass (LP), high-pass (HP), band-pass (BP), and band-stop (BS) characteristics are presented in Table 1 [54]. In the PLFs, a FO exponent term $\alpha$ is introduced in the transfer function of the second-order filter (referred to as the mother filter function). Consequently, the second-order filter characteristics may now be considered as a particular case of the PLFs when $\alpha=1$.

Table 1. Transfer functions and frequency response expressions of the theoretical PLFs ( $\omega_{0}$ : pole frequency, and $Q$ : quality factor).

\begin{tabular}{cccc}
\hline Type & Transfer Function & Magnitude & Phase \\
\hline Low-pass & $H_{\mathrm{D}}^{\mathrm{LP}}(s)=\left(\frac{\omega_{0}^{2}}{s^{2}+\frac{\omega_{0}}{Q} s+\omega_{0}^{2}}\right)^{\alpha}$ & $\frac{1}{\left[1+\left(\frac{\omega}{\omega_{0}}\right)^{4}+\left(\frac{\omega}{\omega_{0}}\right)^{2} \cdot\left(\frac{1}{Q^{2}}-2\right)\right]^{\alpha / 2}}$ & $-\alpha \cdot \tan ^{-1}\left[\frac{\left(\frac{\omega}{\omega_{0}}\right) \cdot \frac{1}{Q}}{1-\left(\frac{\omega}{\omega_{0}}\right)^{2}}\right]$ \\
High-pass & $H_{\mathrm{D}}^{\mathrm{HP}}(s)=\left(\frac{s^{2}}{s^{2}+\frac{\omega_{0}}{Q} s+\omega_{0}^{2}}\right)^{\alpha}$ & $\frac{\left(\frac{\omega}{\omega_{0}}\right)^{2 \alpha}}{\left[1+\left(\frac{\omega}{\omega_{0}}\right)^{4}+\left(\frac{\omega}{\omega_{0}}\right)^{2} \cdot\left(\frac{1}{Q^{2}}-2\right)\right]^{\alpha / 2}}$ & $\alpha \cdot\left\{\pi-\tan ^{-1}\left[\frac{\left(\frac{\omega}{\omega_{0}}\right) \cdot \frac{1}{Q}}{\left.\left.1-\left(\frac{\omega}{\omega_{0}}\right)^{2}\right]\right\}}\right.\right.$ \\
Band-pass & $H_{\mathrm{D}}^{\mathrm{BP}}(s)=\left(\frac{\frac{\omega_{0}}{Q} s}{s^{2}+\frac{\omega_{0}}{Q} s+\omega_{0}^{2}}\right)^{\alpha}$ & $\frac{1}{Q^{\alpha}} \cdot\left(\frac{\omega}{\omega_{0}}\right)^{\alpha}$ & $\alpha \cdot\left\{\frac{\pi}{2}-\tan ^{-1}\left[\frac{\left(\frac{\omega}{\omega_{0}}\right) \cdot \frac{1}{Q}}{1-\left(\frac{\omega}{\omega_{0}}\right)^{2}}\right]\right\}$ \\
Band-stop & $H_{\mathrm{D}}^{\mathrm{BS}}(s)=\left(\frac{s^{2}+\omega_{0}^{2}}{s^{2}+\frac{\omega_{0}}{Q} s+\omega_{0}^{2}}\right)^{\alpha}$ & $\frac{\left.\left.\omega \frac{\omega}{\omega_{0}}\right)^{4}+\left(\frac{\omega}{\omega_{0}}\right)^{2} \cdot\left(\frac{1}{Q^{2}}-2\right)\right]^{\alpha / 2}}{\left[1+\left(\frac{\omega}{\omega_{0}}\right)^{4}+\left(\frac{\omega}{\omega_{0}}\right)^{2} \cdot\left(\frac{1}{Q^{2}}-2\right)\right]^{\alpha / 2}}$ & $-\alpha \cdot \tan ^{-1}\left[\frac{\left(\frac{\omega}{\omega_{0}}\right) \cdot \frac{1}{Q}}{1-\left(\frac{\omega}{\omega_{0}}\right)^{2}}\right]$ \\
\hline
\end{tabular}


This paper presents the optimal modeling of PLFs exhibiting the LP, HP, BP, and BS characteristics. Comparative studies concerning the modeling performance based on three different objective function formulations are presented. A non-parametric statistical null hypothesis test is employed to investigate the similarity in the design performances between the objective functions. The proposed strategy incorporates constraints to ensure a stable PLF approximant. Additional constraints are also incorporated to avoid the placement of zeros in the right-half s-plane. This allows the attainment of inverse PLF (IPLF) characteristics through inversion of the optimal PLF models. Although the S-K method [54] is simpler and computationally superior compared to the proposed technique, the suggested approach demonstrates the following advantages:

(i) The stability of the PLF approximant in S-K method [54] is governed by the stability of the mother filter function. While this guarantees a stable rational approximant, however, the zeros of the filter transfer function may lie on the right-half of $s$ (RHS)plane. For example, while the zeros of the BPPLFs and BSPLFs designed using the S-K method lie on the left-half s-plane; however, the LPPLF and HPPLF models for $\alpha=0.7$ have zeros located at $\{+183.0053,-23.6922,-8.6177,-1.7485\}$ and $\{+0.0055,-0.5718$, $-0.1161,-0.0422\}$, respectively. It may be noted that for the S-K method-based LPPLFs and HPPLFs with $\alpha \in[0.51,0.99]$, one zero lies on the RHS-plane. Consequently, inverting such a transfer function will lead to an unstable inverse-LPPLF (ILPPLF) and inverse-HPPLF (IHPPLF) model. In contrast, the proposed approach can guarantee the generation of stable designs for both PLFs and IPLFs. Hence, this paper also presents the design of IPLFs that has not yet been reported in the literature.

(ii) The modeling accuracy of the proposed optimal PLF approximants, as justified by the Mean Absolute Relative Error (MARE) metric, is significantly better (particularly for the LP, HP, and BP-types) in comparison to the S-K method.

To demonstrate the practical efficacy, discrete component-based circuit realization using CFOAs as active elements for the proposed PLFs and their inverse counterparts with $\alpha=0.5$ is conducted. The experimental results reveal excellent agreement with the theoretical magnitude- and phase-frequency behavior for the PLFs and magnitude responses for the IPLFs. The time-domain and Fast Fourier Transformation (FFT) characteristics of the practical filters are also investigated.

In this paper, Section 2 presents the proposed optimization problem formulation and PLF/IPLF design strategy. The modeling accuracy of the proposed method is investigated using MATLAB simulations in Section 3. Statistical studies concerning the hypothesis test are also presented in this section. Practical circuit implementation and experimental results (magnitude-frequency, phase-frequency, time-domain, and FFT) for the designed filters are presented in Section 4. Finally, the paper concludes in Section 5.

\section{Proposed Technique}

The proposed rational approximant of the PLF is modeled as per (2):

$$
H_{\mathrm{P}}(s)=\frac{a_{N} s^{N}+a_{N-1} s^{N-1}+\ldots+a_{1} s+a_{0}}{s^{N}+b_{N-1} s^{N-1}+b_{N-2} s^{N-2}+\ldots+b_{1} s+b_{0}},
$$

where the coefficients of the numerator and denominator polynomials of $H_{\mathrm{P}}(s)$ are denoted by $a_{k}(k=0,1, \ldots, N)$ and $b_{k}(k=0,1, \ldots, N-1)$, respectively; and $N$ is the order of the filter.

Figure 1 presents the flowchart of the proposed PLF design technique. The magnitude and phase characteristics of the PLFs may be approximated by determining the optimal values of the coefficients of $H_{\mathrm{P}}(s)$ such that the error between the theoretical and proposed responses is minimized. For this purpose, three different objective functions, as defined by (3)-(5), are proposed:

$$
f_{1}=\frac{1}{L} \sum_{i=1}^{L}|| 20 \log _{10}\left|H_{\mathrm{D}}\left(j \omega_{i}\right)\right|-20 \log _{10}\left|H_{\mathrm{P}}\left(j \omega_{i}, X\right)\right|\left|+\frac{180}{\pi}\right| \angle H_{\mathrm{D}}\left(j \omega_{i}\right)-\angle H_{\mathrm{P}}\left(j \omega_{i}, X\right) \mid,
$$




$$
\begin{gathered}
f_{2}=\frac{1}{L} \sum_{i=1}^{L}|| H_{\mathrm{D}}\left(j \omega_{i}\right)|-| H_{\mathrm{P}}\left(j \omega_{i}, X\right)||+\left|\angle H_{\mathrm{D}}\left(j \omega_{i}\right)-\angle H_{\mathrm{P}}\left(j \omega_{i}, X\right)\right|, \\
f_{3}=\frac{1}{L} \sum_{i=1}^{L}\left|1-\frac{\left|H_{\mathrm{P}}\left(j \omega_{i}, X\right)\right|}{\left|H_{\mathrm{D}}\left(j \omega_{i}\right)\right|}\right|+\left|1-\frac{\angle H_{\mathrm{P}}\left(j \omega_{i}, X\right)}{\angle H_{\mathrm{D}}\left(j \omega_{i}\right)}\right|
\end{gathered}
$$

where $L$ denotes the total number of logarithmically spaced sample points in the bandwidth of interest $\omega \in\left[\omega_{\min }, \omega_{\max }\right] \mathrm{rad} / \mathrm{s}$; the decision variables vector is represented by $X=$ $\left[a_{N} a_{N-1} \ldots a_{0} b_{N-1} b_{N-2} \ldots b_{0}\right] ;\left|H_{\mathrm{D}}(j \omega)\right|$ and $\left|H_{\mathrm{P}}(j \omega)\right|$ denote the magnitude of the theoretical PLF and the proposed approximant, respectively; and the phase angles for the theoretical $\left(\angle H_{\mathrm{D}}(j \omega)\right)$ and proposed $\left(\angle H_{\mathrm{P}}(j \omega)\right)$ PLFs are expressed in radians.

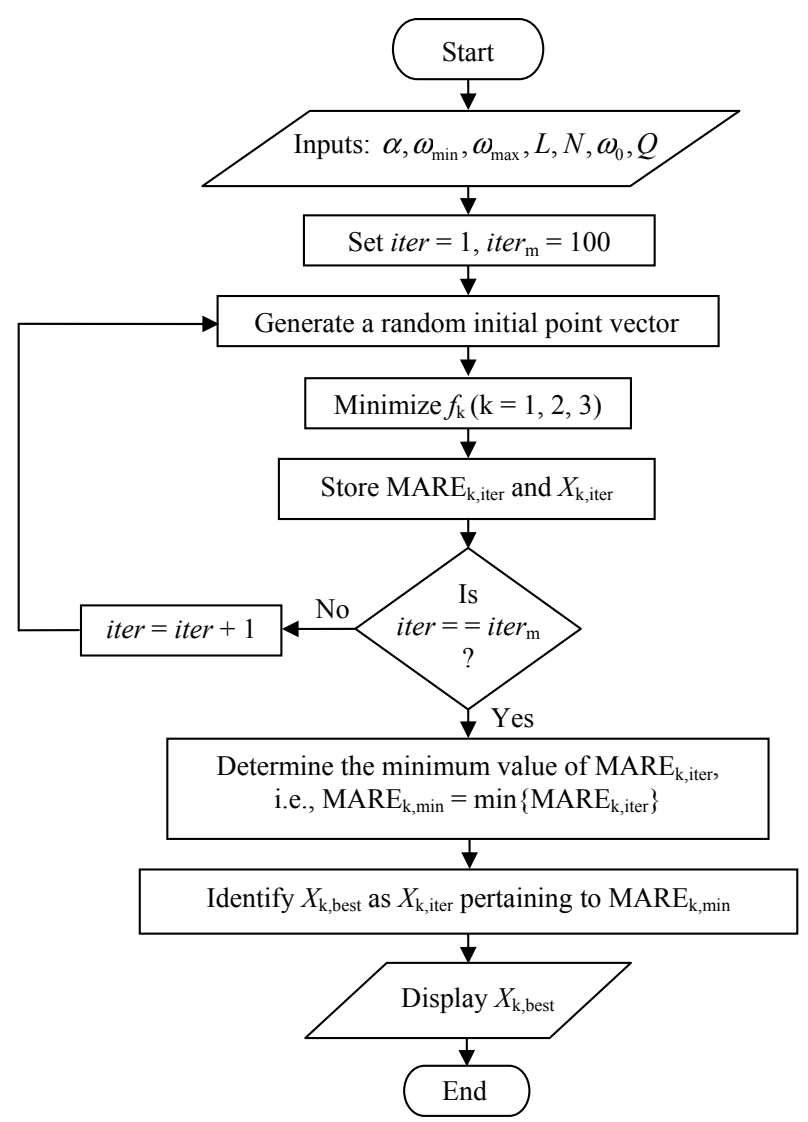

Figure 1. Flowchart of the proposed PLF design technique.

To achieve a stable design, the inequality constraints as given by (6) are incorporated in the proposed optimization method:

$$
\Delta_{1}, \Delta_{2}, \Delta_{3}, \ldots, \Delta_{N}>0,
$$

where $\Delta_{1}=b_{N-1}, \Delta_{2}=\left|\begin{array}{cc}b_{N-1} & b_{N-3} \\ b_{N} & b_{N-2}\end{array}\right|, \Delta_{3}=\left|\begin{array}{ccc}b_{N-1} & b_{N-3} & b_{N-5} \\ b_{N} & b_{N-2} & b_{N-4} \\ 0 & b_{N-1} & b_{N-3}\end{array}\right|, \ldots$,

$\Delta_{N}=\left|\begin{array}{ccccc}b_{N-1} & b_{N-3} & b_{N-5} & \cdots & 0 \\ b_{N} & b_{N-2} & b_{N-4} & \cdots & 0 \\ 0 & b_{N-1} & b_{N-3} & \vdots & 0 \\ \vdots & \vdots & \vdots & \ddots & \vdots \\ 0 & 0 & 0 & 0 & b_{0}\end{array}\right|$ represent the Hurwitz determinants [57], and

$b_{N}=1$. The locations of zeros are also restricted to avoid the right-half $s$-plane by 
incorporating the constraints in (6) with $b_{k}$ substituted with $a_{k}(k=0,1, \cdots, N)$. Thus, the proposed formulation can be solved using a global search constrained optimization problem solver.

The transfer function of the proposed IPLFs can be obtained as $H_{\mathrm{I}}(s)=\left[H_{\mathrm{P}}(s)\right]^{-1}$. As the value of $\alpha$ approaches 1 , it is possible that the coefficients $a_{N}$ and $a_{0}$ of the optimal LPPLF and HPPLF, respectively, may attain a value of 0 . The corresponding ILPPLF would possess one extra zero as compared to the number of poles, while the IHPPLF model will have a pole located at the origin of the s-plane.

To circumvent these particular issues, (i) the proposed ILPPLF transfer function may be represented as $p . H_{\mathrm{I}}(s) /(s+p)$, where $p$ is a large positive number such as 200,500 , or 1000. The accuracy of approximation for the IPLFs increases as $p$ is increased; and (ii) for the case when $a_{0}=0$ arises for the HPPLF, $a_{0}$ may be replaced by a small, positive number $(q)$, for instance, smaller than 0.005. This technique allows the pole of the IHPPLF to be shifted away from the origin towards the left-half of the s-plane, thus, avoiding potential instability issues.

A numerical optimizer requires a user-supplied initial point for the decision variables at the start of the optimization procedure. Subsequently, the optimization algorithm iteratively minimizes the objective function by varying the decision variables. For solving a constrained optimization problem, an additional task of the optimizer is to satisfy the design constraints (i.e., generate a feasible solution). At the end of a single run of the optimization routine (when the maximum number of function evaluations or iterations or function tolerance value is reached), the optimal values of decision variables are obtained.

The final solution quality of a numerical optimization algorithm may be influenced by the choice of the initial point. For solving the global search optimization problems, identifying an appropriate initial point may not be easy. To circumvent this problem, a standard technique is to independently execute the optimization routine several times $\left(\right.$ iter $\left._{\mathrm{m}}\right)$ with randomly chosen initial points in each run. Hence, iter $r_{\mathrm{m}}$ number of near-global optimal solution vectors can be generated in this process. The best decision variables vector ( $\left.X_{\text {best }}\right)$ is selected as the one that achieves the smallest error (MARE in the present case) from the iter $_{\mathrm{m}}$ solutions. The previously-mentioned strategy is employed in this paper for the optimal modeling of PLFs.

\section{MATLAB Simulations and Performance Analysis}

The optimization procedures to minimize the objective functions (3)-(5) are implemented in MATLAB programming language using the function fmincon (algorithm: active-set) with the following parameter settings: maximum number of function evaluations $=50,000$; maximum number of iterations $=50,000$; and termination tolerance on the function value $=10^{-10}$. In each trial run, the initial point for the decision variables vector is randomly chosen from a uniform distribution in the interval $[0,50]$. For each design case, iter $_{\mathrm{m}}=100$ independent trial runs of the optimization routine for each objective function are carried out.

Quantitative comparisons of the design accuracy are carried out based on the MARE metric as defined by (7):

$$
\text { MARE }=\frac{1}{L}\left[\sum_{i=1}^{L}\left|1-\frac{\left|H_{\mathrm{P}}\left(j \omega_{i}\right)\right|}{\left|H_{\mathrm{D}}\left(j \omega_{i}\right)\right|}\right|+\sum_{i=1}^{L}\left|1-\frac{\angle H_{\mathrm{P}}\left(j \omega_{i}\right)}{\angle H_{\mathrm{D}}\left(j \omega_{i}\right)}\right|\right] .
$$

For demonstration purposes, the values of $L, \alpha, N, \omega_{\min }, \omega_{\max }, \omega_{0}$, and $Q$ are chosen as $1000,\{0.3,0.5,0.7\}, 4,0.01 \mathrm{rad} / \mathrm{s}, 100 \mathrm{rad} / \mathrm{s}, 1 \mathrm{rad} / \mathrm{s}$, and $1 / \sqrt{2}$, respectively. Detailed results for various other values of $\alpha$ are also available from the authors and can be shared with interested readers. 


\subsection{Statistical Analyses and Performance Evaluation}

\subsubsection{Comparisons Based on the MARE Metric}

Statistical comparisons about the MARE metric were carried out to determine the average performance of the proposed optimization strategy for the design of PLFs using the three objective functions. The minimum ( $\mathrm{min}$ ), maximum (max), mean, and standard deviation (SD) indices for the various design orders are shown in Table 2. Graphical comparisons for the MARE attained for the designed PLFs are presented using boxplots in Figure 2. In the case of LPPLFs, we found that: (i) for $\alpha=0.3, f_{3}$ attained the best performance for all the statistical indices; (ii) the most accurate model (i.e., the design with the minimum value of MARE (MARE $\left.\mathrm{min}_{\min }\right)$ for $\alpha=0.5$ was achieved by $f_{1}\left(1.11 \times 10^{-4}\right)$, although $f_{2}$ yielded the best results for the other indices; and (iii) very similar performances for MARE $\min$ were achieved for $\alpha=0.7$, with $f_{3}(0.0068)$ attaining marginally better accuracy.

However, $f_{3}$ distinctly outperformed the other two objective functions regarding the max, mean, and SD values. For the HPPLFs, (i) $f_{3}$ achieved significantly better MARE $\mathrm{min}_{\text {in }}$ (0.0081) as compared to $f_{1}(0.0371)$ and $f_{2}(0.0380)$ for $\alpha=0.3$. However, the max, mean, and SD performances for $f_{3}$ were the worst among the three functions; (ii) with $\alpha=0.5, f_{1}$ yielded inferior performance about the min, mean, and SD indices, while the best values concerning MARE $E_{\text {min }}$ and mean MARE were achieved by $f_{3}\left(1.20 \times 10^{-5}\right)$ and $f_{2}(0.1516)$, respectively; and (iii) for $\alpha=0.7, f_{1}$ attained the most accurate model $\left(\mathrm{MARE}_{\min }=0.0068\right.$ ), while $f_{2}$ yielded the best performance for all the other indices.

Table 2. Statistical comparisons of the MARE for designed PLFs.

\begin{tabular}{|c|c|c|c|c|c|c|c|c|c|c|}
\hline \multirow{2}{*}{ Filter } & \multirow{2}{*}{ Index } & \multicolumn{3}{|c|}{$\alpha=0.3$} & \multicolumn{3}{|c|}{$\alpha=0.5$} & \multicolumn{3}{|c|}{$\alpha=0.7$} \\
\hline & & $f_{1}$ & $f_{2}$ & $f_{3}$ & $f_{1}$ & $f_{2}$ & $f_{3}$ & $f_{1}$ & $f_{2}$ & $f_{3}$ \\
\hline \multirow{4}{*}{ LPPLF } & Min & 0.0097 & 0.0100 & 0.0081 & $1.11 \times 10^{-4}$ & $1.41 \times 10^{-4}$ & $1.54 \times 10^{-4}$ & 0.0072 & 0.0073 & 0.0068 \\
\hline & Max & 2.6271 & 2.3788 & 1.4640 & 2.9436 & 1.8702 & 1.9990 & 2.7724 & 2.7217 & 1.5765 \\
\hline & Mean & 0.1644 & 0.1960 & 0.0647 & 0.1095 & 0.0379 & 0.0740 & 0.1174 & 0.1410 & 0.0491 \\
\hline & SD & 0.4655 & 0.4563 & 0.1877 & 0.4031 & 0.1910 & 0.3262 & 0.3996 & 0.3878 & 0.1707 \\
\hline \multirow{4}{*}{ HPPLF } & Min & 0.0371 & 0.0380 & 0.0081 & $2.55 \times 10^{-4}$ & $2.06 \times 10^{-4}$ & $1.20 \times 10^{-5}$ & 0.0068 & 0.0415 & 0.0308 \\
\hline & Max & 3.2533 & 3.0948 & 4.8429 & 4.7061 & 5.3711 & 5.3368 & 5.7460 & 2.2993 & 7.6727 \\
\hline & Mean & 0.2869 & 0.1752 & 0.5542 & 0.3599 & 0.1516 & 0.1725 & 0.3906 & 0.1994 & 0.2710 \\
\hline & SD & 0.5413 & 0.3953 & 0.9991 & 1.0042 & 0.6603 & 0.6509 & 0.8299 & 0.3567 & 0.9709 \\
\hline \multirow{4}{*}{ BPPLF } & Min & 0.0850 & 0.0822 & 0.0785 & 0.0786 & 0.0758 & 0.0735 & 0.0568 & 0.0557 & 0.0540 \\
\hline & Max & 7.2483 & 5.6081 & 6.5838 & 4.9242 & 3.0704 & 8.2371 & 3.2517 & 7.1117 & 3.9668 \\
\hline & Mean & 0.5429 & 0.4603 & 0.3324 & 0.4141 & 0.3461 & 0.3522 & 0.3440 & 0.2805 & 0.2651 \\
\hline & SD & 0.9948 & 0.9361 & 0.7146 & 0.7051 & 0.5823 & 0.8862 & 0.6418 & 0.8186 & 0.5066 \\
\hline \multirow{4}{*}{ BSPLF } & Min & 0.0148 & 0.0564 & 0.0427 & 0.0133 & 0.0123 & 0.0438 & 0.0101 & 0.0090 & 0.0385 \\
\hline & Max & 5.9545 & 7.6578 & 8.9775 & 5.6246 & 8.2135 & 7.5578 & 7.2166 & 7.0028 & 7.5591 \\
\hline & Mean & 0.4435 & 0.6127 & 1.5306 & 0.5749 & 0.7712 & 1.2279 & 0.8967 & 0.8219 & 1.4433 \\
\hline & SD & 0.9858 & 1.5685 & 2.1678 & 1.0939 & 1.5658 & 1.6760 & 1.6799 & 1.4094 & 1.8164 \\
\hline
\end{tabular}

In the case of BPPLFs, it is revealed that: (i) for all the cases, the best performer about MARE $_{\text {min }}$ is $f_{3}$; (ii) regarding the mean and SD indices, $f_{2}$ attained the minimum value for $\alpha=0.5$ and $f_{3}$ for the other two orders; and (iii) the best results for the max MARE were achieved by $f_{2}$ (5.6081), $f_{2}$ (3.0704), and $f_{1}$ (3.2517) for $\alpha=0.3,0.5$, and 0.7 , respectively. Comparisons for the designed BSPLFs show that $f_{1}$ and $f_{2}$ achieved the best values for all the statistical indices with $\alpha=0.3$ and $\alpha=0.7$, respectively. In the case of $\alpha=0.5$, the most accurate model is attained by $f_{2}\left(\mathrm{MARE}_{\min }=0.0123\right)$, whereas $f_{1}$ yields superior performance for the other three indices. 


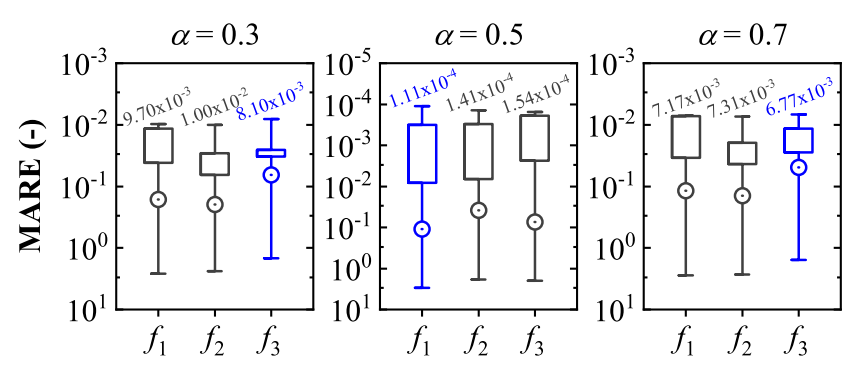

(a)

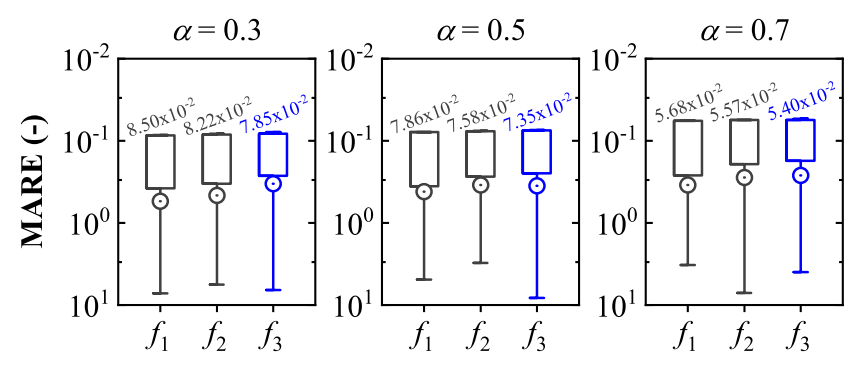

(c)

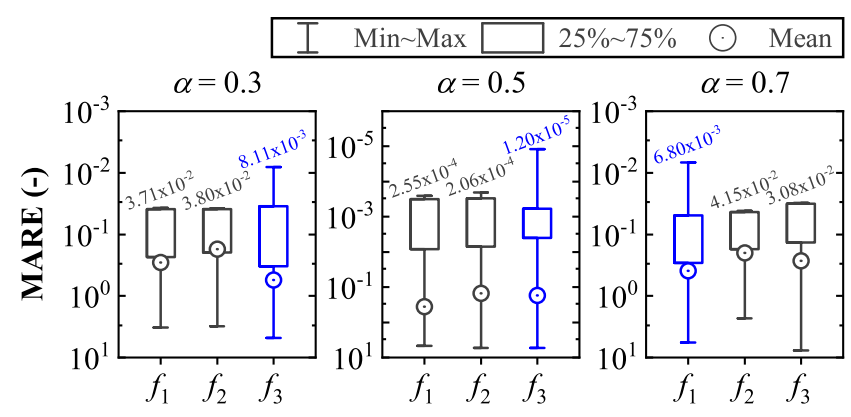

(b)

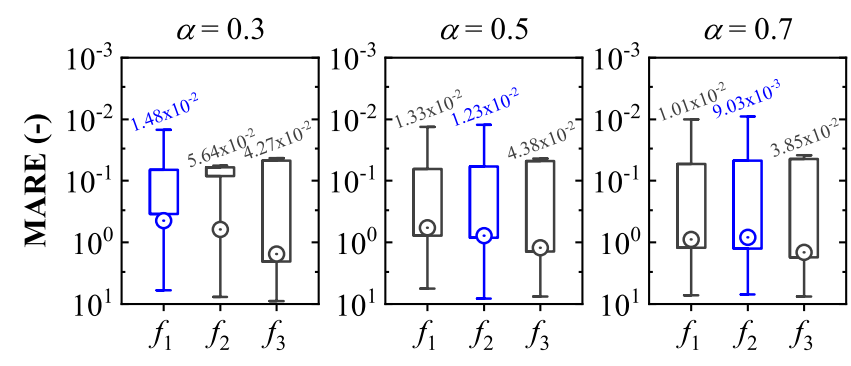

(d)

Figure 2. MARE comparison using boxplots for the (a) LPPLF, (b) HPPLF, (c) BPPLF, and (d) BSPLF. Note: The most accurate model (lowest $\mathrm{MARE}_{\min }$ ) for each case is indicated in blue.

\subsubsection{Comparisons Based on the Wilcoxon Rank-Sum Hypothesis Test}

Pair-wise comparisons based on the Wilcoxon rank-sum test for the PLFs designed using $f_{1}, f_{2}$, and $f_{3}$ are conducted to determine whether a statistically significant difference exists in the modeling performance [58]. If no significant difference exists in the design accuracy, then a similar average-case modeling error performance can be expected from all the proposed objective functions. Consequently, all the three objective functions may exhibit similar robustness.

Thus, in terms of solution consistency, the objective functions demonstrate similar performance. For this purpose, the null hypothesis $\left(\mathrm{H}_{0}\right.$ : 'equality of medians for the MARE metric') is considered at a confidence level of $95 \%$. The decision index is represented by $\mathrm{H}$, where $\mathrm{H}=0 / 1$ indicates that $\mathrm{H}_{0}$ cannot/can be rejected. Table 3 presents the Wilcoxon rank-sum test results along with the $p$-value ( $p$-val) index. A smaller $p$-val indicates stronger evidence in favor of rejection of $\mathrm{H}_{0}$.

It is revealed that: (i) $\mathrm{H}_{0}$ is rejected for all the pair-wise combinations concerning the LPPLF, HPPLF, and BSPLF with $\alpha=0.3,0.7$, and 0.3 , respectively; (ii) only one case (HPPLF with $\alpha=0.3$ ) exists where all the combinations may result in non-rejection of $\mathrm{H}_{0}$; (iii) for comparisons involving all the three design orders for a particular pair, the hypothesis can be rejected for $f_{1} / f_{2}$ with the BSPLF, $f_{2} / f_{3}$ with the LPPLF, and $f_{1} / f_{3}$ for the BPPLF and BSPLF, whereas $\mathrm{H}_{0}$ may not be rejected for the BPPLF with $f_{2} / f_{3}$; and (iv) across all the PLFs, 9,8 , and 5 cases out of 12 exist for $f_{1} / f_{2}, f_{1} / f_{3}$, and $f_{2} / f_{3}$, respectively, that lead to the rejection of $\mathrm{H}_{0}$. Overall, it may be concluded from the statistical analysis that, in terms of attaining a similar performance consistency for all the design cases, the three objective functions cannot be used interchangeably.

The optimal coefficients of the PLFs that achieve the smallest value of MARE for each of the three objective functions are presented in Appendix A. The MATLAB-simulated magnitude- and phase-frequency responses for the most accurate (least $\mathrm{MARE}_{\min }$ ) proposed LPPLFs, HPPLFs, BPPLFs, and BSPLFs are presented in Figures 3-6, respectively. The plots for the corresponding IPLFs are also illustrated in these figures. The values of $p$ 
and $q$ are considered as 1000 and $10^{-6}$ for the ILPPLF and IHPPLF, respectively, for $\alpha=0.5$ and 0.7. We observed that all the design cases attained good agreement with the theoretical responses.

Table 3. Wilcoxon rank-sum test results for the designed PLFs.

\begin{tabular}{|c|c|c|c|c|c|c|c|c|c|c|}
\hline \multirow{2}{*}{ Filter } & \multirow{2}{*}{ Index } & \multicolumn{3}{|c|}{$f_{1}$ vs. $f_{2}$} & \multicolumn{3}{|c|}{$f_{1}$ vs. $f_{3}$} & \multicolumn{3}{|c|}{$f_{2}$ vs. $f_{3}$} \\
\hline & & $\alpha=0.3$ & $\alpha=0.5$ & $\alpha=0.7$ & $\alpha=0.3$ & $\alpha=0.5$ & $\alpha=0.7$ & $\alpha=0.3$ & $\alpha=0.5$ & $\alpha=0.7$ \\
\hline \multirow{2}{*}{ LPPLF } & $p$-val & $3.3 \times 10^{-8}$ & 0.9173 & $8.0 \times 10^{-9}$ & $9.7 \times 10^{-4}$ & 0.0911 & 0.1443 & $1.5 \times 10^{-6}$ & 0.0013 & $1.4 \times 10^{-8}$ \\
\hline & $\mathrm{H}$ & 1 & 0 & 1 & 1 & 0 & 0 & 1 & 1 & 1 \\
\hline \multirow{2}{*}{ HPPLF } & $p$-val & 0.7369 & 0.0303 & $3.7 \times 10^{-6}$ & 0.5551 & 0.7966 & $1.1 \times 10^{-8}$ & 0.2087 & 0.6574 & $6.1 \times 10^{-6}$ \\
\hline & $\mathrm{H}$ & 0 & 1 & 1 & 0 & 0 & 1 & 0 & 0 & 1 \\
\hline \multirow{2}{*}{ BPPLF } & $p$-val & 0.2503 & 0.0211 & $8.8 \times 10^{-6}$ & 0.0474 & 0.0417 & 0.0322 & 0.1626 & 0.1416 & 0.8902 \\
\hline & $\mathrm{H}$ & 0 & 1 & 1 & 1 & 1 & 1 & 0 & 0 & 0 \\
\hline \multirow{2}{*}{ BSPLF } & $p$-val & $1.0 \times 10^{-6}$ & $6.6 \times 10^{-4}$ & $1.1 \times 10^{-4}$ & 0.0032 & 0.0294 & 0.0276 & 0.0087 & 0.1739 & 0.0708 \\
\hline & $\mathrm{H}$ & 1 & 1 & 1 & 1 & 1 & 1 & 1 & 0 & 0 \\
\hline
\end{tabular}

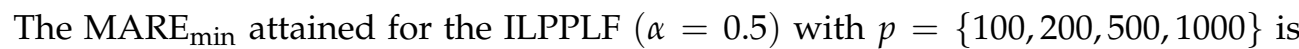
$\{0.0919,0.0439,0.0164,0.0079\}$. In the case of IHPPLF for $\alpha=0.5$ with $q=\{0.005,0.002$, $0.001,0.0001\}$, the MARE $\min$ is obtained as $\{0.0447,0.0170,0.0084,0.0008\}$. These results confirm that the approximation accuracy of the ILPPLF and IHPPLF improves for larger values of $p$ and smaller values of $q$, respectively. The MARE $E_{\min }$ attained for the proposed inverse BPPLFs (IBPPLFs) with $\alpha=\{0.3,0.5,0.7\}$ is $\{0.0790,0.0745,0.0548\}$; the same for the inverse BSPLFs (IBSPLFs) is $\{0.0147,0.0121,0.0092\}$.

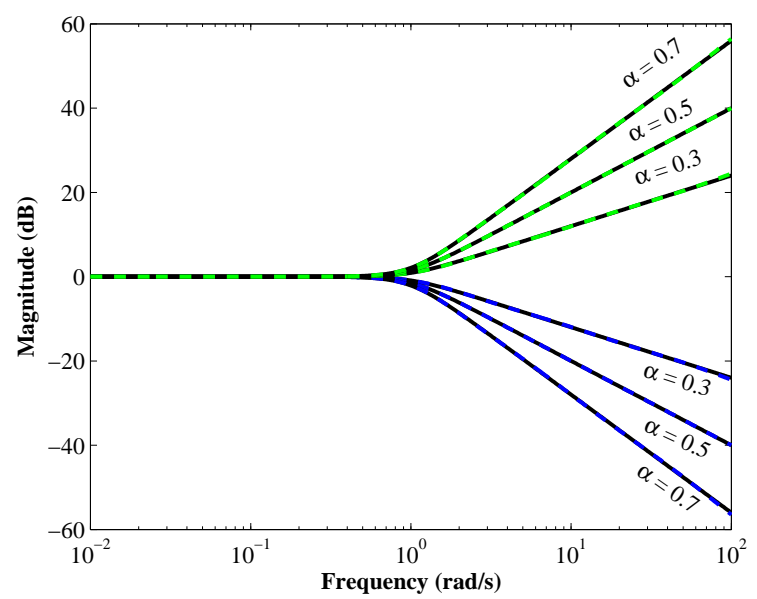

(a)

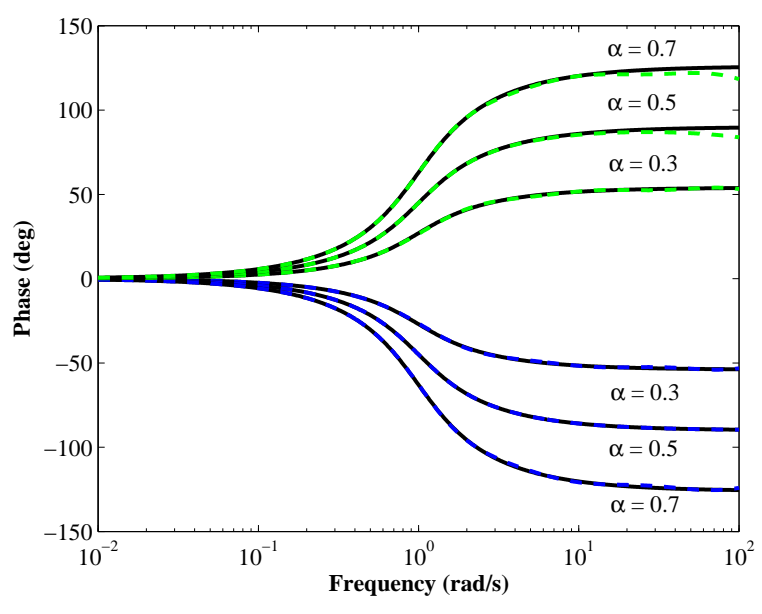

(b)

Figure 3. (a) Magnitude and (b) phase-frequency responses of the proposed LPPLFs (dashed blue) and ILPPLFs (dashed green) as compared to the theoretical ones (solid black). 


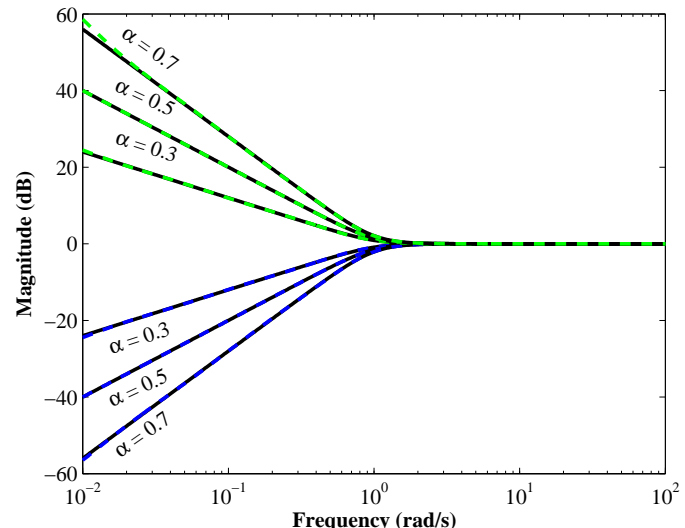

(a)

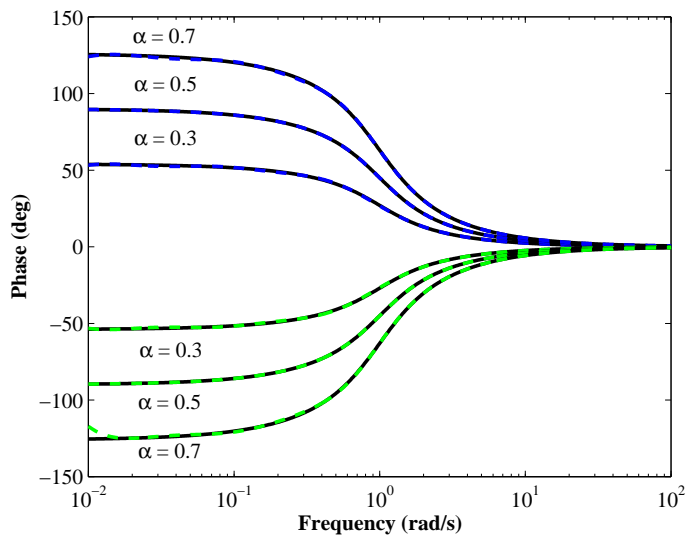

(b)

Figure 4. (a) Magnitude and (b) phase-frequency responses of the proposed HPPLFs (dashed blue) and IHPPLFs (dashed green) as compared to the theoretical ones (solid black).

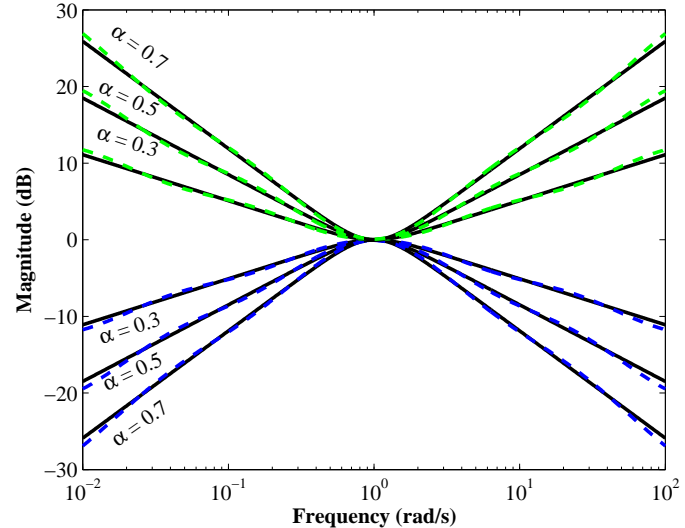

(a)

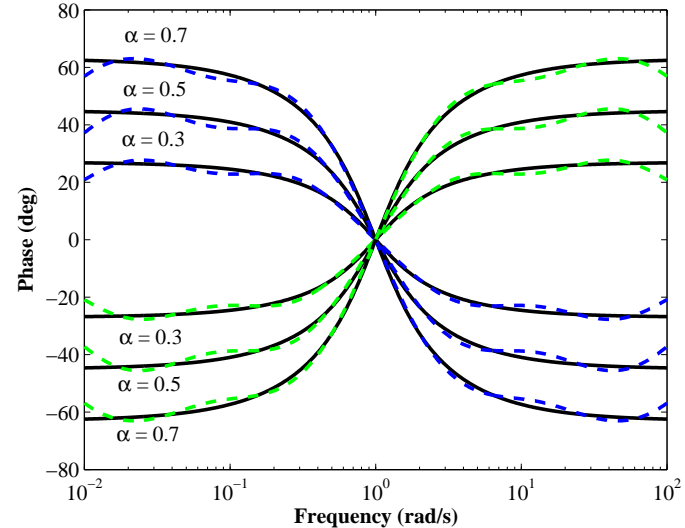

(b)

Figure 5. (a) Magnitude and (b) phase-frequency responses of the proposed BPPLFs (dashed blue) and IBPPLFs (dashed green) as compared to the theoretical ones (solid black).

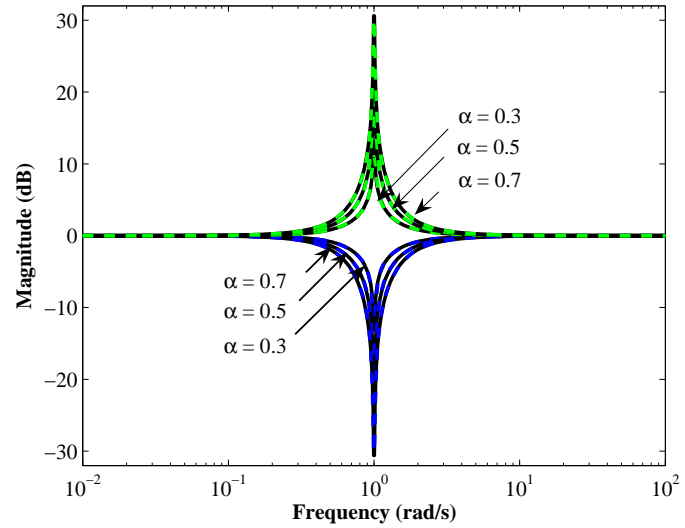

(a)

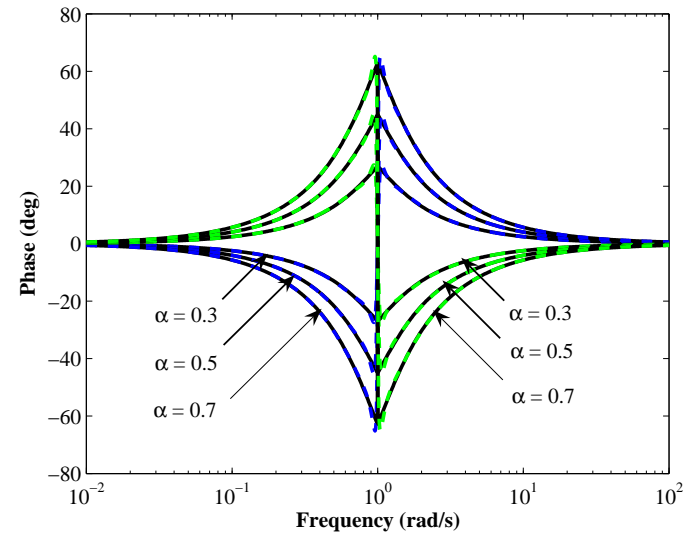

(b)

Figure 6. (a) Magnitude and (b) phase-frequency responses of the proposed BSPLFs (dashed blue) and IBSPLFs (dashed green) as compared to the theoretical ones (solid black). 


\subsection{Comparison with the Literature}

The proposed most accurate PLFs are compared with the published literature [54] based on the MARE metric, as shown in Table 4. The proposed designs outperform the reported models for all the considered cases by achieving the least MARE values. The improvements in the percentage absolute relative error $\left(100 \times\left|\frac{\mathrm{MARE}_{\text {Prop }}-\mathrm{MARE}_{\text {Rep }}}{\mathrm{MARE}_{\text {Rep }}}\right|\right)$, where MARE $\mathrm{Prop}_{\text {and }}$ MARE $\mathrm{Rep}_{\text {are }}$ a the MARE values achieved for the proposed model and [54], respectively, for the LPPLF, HPPLF, BPPLF, and BSPLF with $\alpha=\{0.3,0.5,0.7\}$ are $\{47.40,58.58,83.41\} \%,\{48.73,87.22,83.41\} \%,\{7.75,16.85,27.71\} \%$, and $\{18.23,10.87$, $8.16\} \%$, respectively. Graphical visualizations of these percentage improvements for all the proposed designs are shown using bar plots in Figure 7. Improvements over [54] for the proposed LPPLF and HPPLF are distinctly pronounced as compared to those of the BPPLF and BSPLF. Hence, the proposed technique may be considered as a more accurate modeling tool when compared against [54].

Table 4. Comparison of the most accurate proposed PLFs with the published literature [54] in terms of the MARE metric.

\begin{tabular}{ccccc}
\hline Filter & Reference & $\boldsymbol{\alpha}=\mathbf{0 . 3}$ & $\boldsymbol{\alpha}=\mathbf{0 . 5}$ & $\boldsymbol{\alpha}=\mathbf{0 . 7}$ \\
\hline \multirow{2}{*}{ LPPLF } & {$[54]$} & 0.0154 & $2.68 \times 10^{-4}$ & 0.0410 \\
& Proposed & 0.0081 & $1.11 \times 10^{-4}$ & 0.0068 \\
HPPLF & [54] & 0.0158 & $9.39 \times 10^{-5}$ & 0.0410 \\
& Proposed & 0.0081 & $1.20 \times 10^{-5}$ & 0.0068 \\
BPPLF & [54] & 0.0851 & 0.0884 & 0.0747 \\
& Proposed & 0.0785 & 0.0735 & 0.0540 \\
BSPLF & [54] & 0.0181 & 0.0138 & 0.0098 \\
& Proposed & 0.0148 & 0.0123 & 0.0090 \\
\hline
\end{tabular}
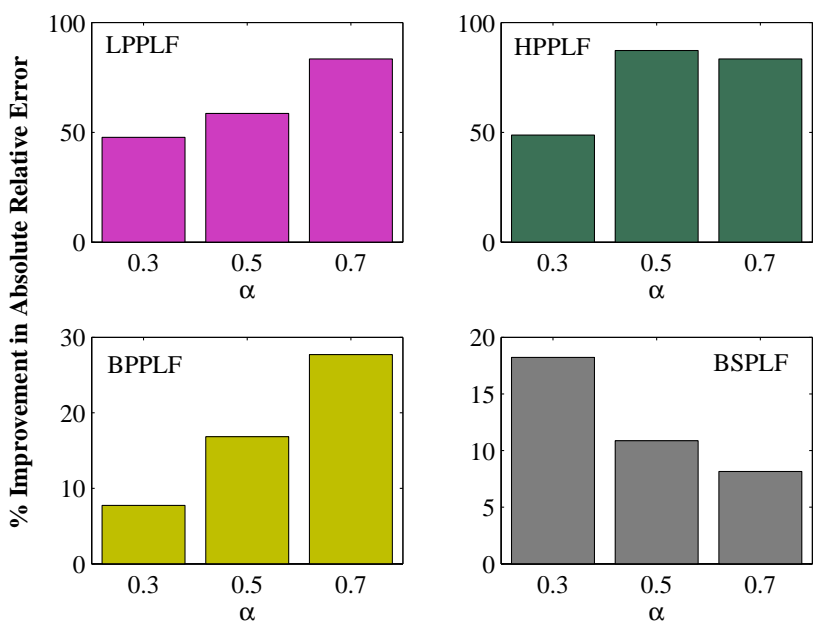

Figure 7. Percentage improvement in absolute relative error of the proposed PLFs with respect to [54].

Comparisons about the computational time $\left(t_{\mathrm{c}}\right)$ required by the S-K method [54] and the proposed technique for the design of PLFs with $\alpha=0.5$ are conducted in the following environment - CPU: Intel i3 @ $1.70 \mathrm{GHz}$, RAM: 2.0 GB, Operating System: Windows 7 (64 bit), and Software: MATLAB 2014a. The $t_{c}$ required by [54] for the design of LPPLF, HPPLF, BPPLF, and BSPLF is 1.601, 1.600, 1.665, and $1.663 \mathrm{~s}$, respectively. For the proposed technique with objective functions $\left\{f_{1}, f_{2}, f_{3}\right\}$, the $t_{\mathrm{c}}$ (expressed in seconds) required to complete 100 iterations is, respectively, obtained as $\{254.036,230.221,215.673\}$, $\{251.964,213.028,260.650\},\{265.070,296.818,291.986\}$, and $\{273.787,230.171,198.241\}$.

These results show that no specific objective function can attain the smallest value of $t_{\mathrm{c}}$ for all the designed PLFs. In terms of computational efficiency, the proposed strategy is 
inferior to the reported technique [54]. However, since the PLF approximation is carried out offline, the higher $t_{\mathrm{c}}$ of the proposed method may be traded-off in favor of achieving superior modeling accuracy compared to the S-K method [54].

\section{Experimental Validation}

CFOAs are popular analog signal processing integrated circuits that offer a high slew rate, gain-bandwidth decoupling, and smaller power consumption compared to operational amplifiers [59]. Due to their versatility, CFOAs have been widely employed to implement FO filters $[19,32,41,51,60]$.

Discrete components-based circuit realization of the proposed PLFs is carried out by employing the CFOA as an active element in a follow-the-leader feedback topology [19]. The circuit diagram for the generalized PLF and IPLF implementation is presented in Figure 8 . The total numbers of CFOAs, capacitors, and resistors required to realize the proposed $N$ th-order approximant are $N+2, N$, and $3 N+4$, respectively.
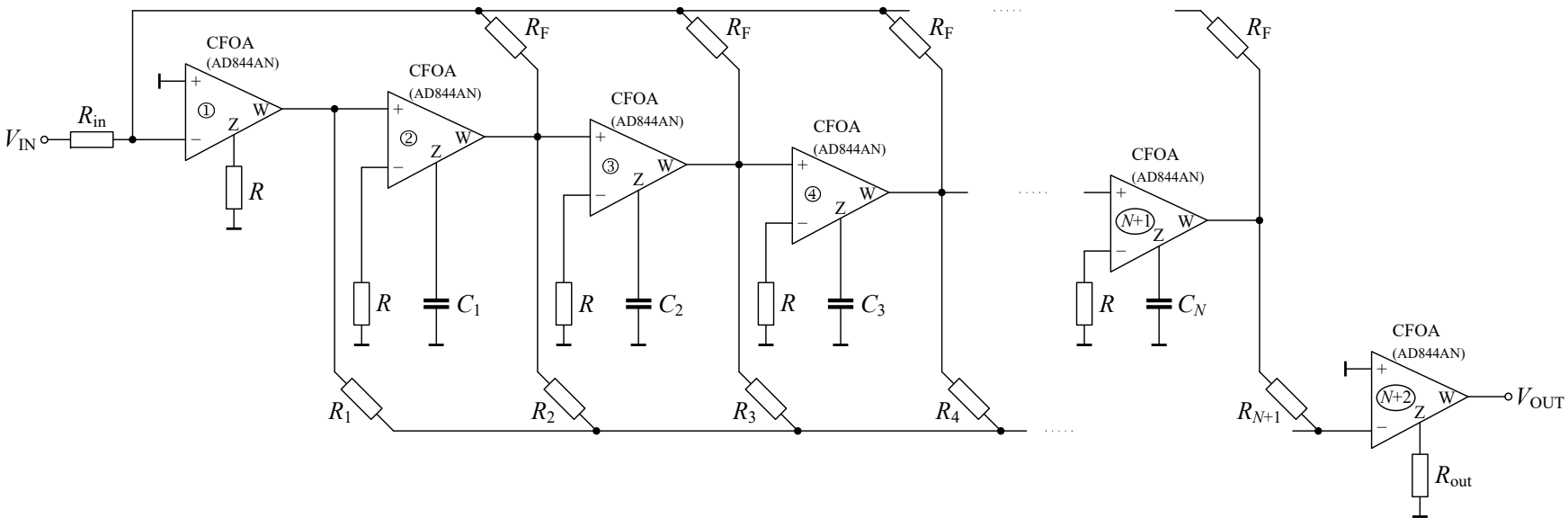

Figure 8. CFOA-based circuit implementation of the proposed PLFs/IPLFs.

The proposed circuit resulted in a reduced component count compared to [54] where the PLF implementation requires $N+4$ operational amplifiers, $N$ capacitors, and $3 N+8$ resistors. Thus, irrespective of the value of $N$, the circuit reported in [54] requires two extra op-amps and four additional resistors as compared to the proposed one. The general transfer function of the proposed circuit is given by (8):

$$
\frac{V_{\mathrm{OUT}}(s)}{V_{\mathrm{IN}}(s)}=\frac{R_{\mathrm{out}}}{R_{\mathrm{in}}} \times \frac{\frac{R}{R_{1}} s^{N}+\sum_{i=1}^{N} \frac{s^{N-i}}{R_{1} R^{i-1} \prod_{k=1}^{i} \frac{R_{k+1}}{R_{k}} C_{k}}}{s^{N}+\sum_{i=1}^{N} \frac{s^{N-i}}{R_{\mathrm{F}} R^{i-1} \prod_{k=1}^{i} C_{k}}} .
$$

As a representative, the circuit implementation steps for the proposed PLFs and IPLFs of LP, HP, BP, and BS types, whose transfer functions for $\alpha=0.5$ are given by (9)-(16), are presented below.

$$
\begin{gathered}
H_{\mathrm{P}}^{\mathrm{LP}}(s)=\frac{s^{3}+3.3454 s^{2}+3.9298 s+1.6952}{s^{4}+4.0523 s^{3}+6.5467 s^{2}+5.1288 s+1.6952}, \\
H_{\mathrm{P}}^{\mathrm{HP}}(s)=\frac{s^{4}+2.6111 s^{3}+2.5477 s^{2}+0.9238 s}{s^{4}+3.3182 s^{3}+4.6441 s^{2}+3.2008 s+0.9238}, \\
H_{\mathrm{P}}^{\mathrm{BP}}(s)=\frac{0.0727 s^{4}+8.6573 s^{3}+56.5588 s^{2}+8.6576 s+0.0727}{s^{4}+26.6767 s^{3}+58.9923 s^{2}+26.6771 s+1.0001},
\end{gathered}
$$




$$
\begin{gathered}
H_{\mathrm{P}}^{\mathrm{BS}}(s)=\frac{0.9999 s^{4}+0.6374 s^{3}+2.0280 s^{2}+0.6374 s+1.0001}{s^{4}+1.3406 s^{3}+2.2471 s^{2}+1.3407 s+1.0001}, \\
H_{\mathrm{I}}^{\mathrm{LP}}(s)=\frac{200 s^{4}+810.4600 s^{3}+1309.3000 s^{2}+1025.8000 s+339.0400}{s^{4}+203.3454 s^{3}+673.0098 s^{2}+787.6552 s+339.0400}, \\
H_{\mathrm{I}}^{\mathrm{HP}}(s)=\frac{s^{4}+3.3182 s^{3}+4.6441 s^{2}+3.2008 s+0.9238}{s^{4}+2.6111 s^{3}+2.5477 s^{2}+0.9238 s+0.0020}, \\
H_{\mathrm{I}}^{\mathrm{BP}}(s)=\frac{13.7552 s^{4}+366.9422 s^{3}+811.4484 s^{2}+366.9477 s+13.7565}{s^{4}+119.0825 s^{3}+777.9752 s^{2}+119.0867 s+1}, \\
H_{\mathrm{I}}^{\mathrm{BS}}(s)=\frac{1.0001 s^{4}+1.3407 s^{3}+2.2473 s^{2}+1.3408 s+1.0002}{s^{4}+0.6375 s^{3}+2.0282 s^{2}+0.6375 s+1.0002} .
\end{gathered}
$$

The design steps are described as follows:

Step 1: Set $N=4$ in (8). Therefore, six CFOAs, four capacitors, and 16 resistors are required to construct the circuit. The transfer function for the CFOA-based circuit is given by (17):

$$
\frac{V_{\mathrm{OUT}}(s)}{V_{\mathrm{IN}}(s)}=\frac{R_{\text {out }}}{R_{\text {in }}} \times \frac{\frac{R}{R_{1}} s^{4}+\frac{s^{3}}{R_{2} C_{1}}+\frac{s^{2}}{R R_{3} C_{1} C_{2}}+\frac{s}{R^{2} R_{4} C_{1} C_{2} C_{3}}+\frac{1}{R^{3} R_{5} C_{1} C_{2} C_{3} C_{4}}}{s^{4}+\frac{s^{3}}{R_{\mathrm{F}} C_{1}}+\frac{s^{2}}{R R_{\mathrm{F}} C_{1} C_{2}}+\frac{s}{R^{2} R_{\mathrm{F}} C_{1} C_{2} C_{3}}+\frac{1}{R^{3} R_{\mathrm{F}} C_{1} C_{2} C_{3} C_{4}}} .
$$

Step 2: Select the desired center frequency for the filter. For instance, a center frequency of $1 \mathrm{kHz}$ is used here.

Step 3: Set the values of $R, R_{\mathrm{F}}, R_{\text {out }}$, and $R_{\mathrm{in}}$. Note that the resistor ratio $R_{\text {out }} / R_{\mathrm{in}}$ helps in gain adjustment.

Step 4: Compare the coefficients of (17) with the corresponding coefficients of the denormalized transfer functions from (9)-(16) and determine the values of the remaining passive components for the filter.

Step 5: Choose the nearest values of the passive components from the E24 industrial series for the resistors and the E12 series for the capacitors. The passive components required to implement the proposed PLFs and IPLFs are presented in Tables 5 and 6, respectively. For better accuracy, $R_{\text {out }}$ was selected from the E48 series for the IHPPLF.

Table 5. Values of the passive components for the realization of the proposed PLFs $(\alpha=0.5)$ (Note: All resistances are in $\mathrm{k} \Omega$, and all capacitances are in $\mathrm{nF}$ ).

\begin{tabular}{cccccccccccccc}
\hline Filter & $\boldsymbol{R}_{\text {out }}$ & $\boldsymbol{R}_{\text {in }}$ & $\boldsymbol{R}$ & $\boldsymbol{R}_{\mathbf{F}}$ & $\boldsymbol{R}_{\mathbf{1}}$ & $\boldsymbol{R}_{\mathbf{2}}$ & $\boldsymbol{R}_{\mathbf{3}}$ & $\boldsymbol{R}_{\mathbf{4}}$ & $\boldsymbol{R}_{\mathbf{5}}$ & $\boldsymbol{C}_{\boldsymbol{1}}$ & $\boldsymbol{C}_{\mathbf{2}}$ & $\boldsymbol{C}_{\boldsymbol{3}}$ & $\boldsymbol{C}_{\boldsymbol{4}}$ \\
\hline LPPLF & 10 & 10 & 10 & 10 & $\infty$ & 39 & 20 & 13 & 10 & 3.9 & 10 & 22 & 47 \\
HPPLF & 10 & 10 & 10 & 10 & 10 & 13 & 18 & 36 & $\infty$ & 4.7 & 12 & 22 & 56 \\
BPPLF & 10 & 10 & 10 & 10 & 130 & 30 & 10 & 30 & 130 & 0.56 & 6.8 & 33 & 390 \\
BSPLF & 10 & 10 & 10 & 10 & 10 & 20 & 11 & 20 & 10 & 12 & 10 & 27 & 22 \\
\hline
\end{tabular}

Table 6. Values of the passive components for the realization of the proposed IPLFs $(\alpha=0.5)$ (Note: All resistances are in $\mathrm{k} \Omega$, and all capacitances are in $\mathrm{nF}$ ).

\begin{tabular}{cccccccccccccc}
\hline Filter & $\boldsymbol{R}_{\text {out }}$ & $\boldsymbol{R}_{\text {in }}$ & $\boldsymbol{R}$ & $\boldsymbol{R}_{\mathbf{F}}$ & $\boldsymbol{R}_{\mathbf{1}}$ & $\boldsymbol{R}_{\mathbf{2}}$ & $\boldsymbol{R}_{\mathbf{3}}$ & $\boldsymbol{R}_{\mathbf{4}}$ & $\boldsymbol{R}_{\mathbf{5}}$ & $\boldsymbol{C}_{\boldsymbol{1}}$ & $\boldsymbol{C}_{\boldsymbol{2}}$ & $\boldsymbol{C}_{\mathbf{3}}$ & $\boldsymbol{C}_{\boldsymbol{4}}$ \\
\hline ILPPLF & 30 & 20 & 20 & 20 & 0.1 & 5.1 & 10 & 15 & 20 & 0.039 & 2.2 & 6.8 & 18 \\
IHPPLF & 11.5 & 10 & 200 & 200 & 200 & 160 & 110 & 56 & 0.43 & 0.33 & 0.82 & 2.2 & 390 \\
IBPPLF & 51 & 51 & 51 & 51 & 3.6 & 16 & 51 & 16 & 3.6 & 0.027 & 0.47 & 22 & 390 \\
IBSPLF & 51 & 51 & 51 & 51 & 51 & 24 & 47 & 24 & 51 & 4.7 & 1.0 & 10 & 2.2 \\
\hline
\end{tabular}


Practical circuit implementations were carried out using the Analog Devices AD844ANtype CFOAs. Supply voltage of 12 volts for the chips was provided from the Agilent E3630A power supply. The magnitude-frequency and phase-frequency measurements were conducted using the OMICRON Lab Bode 100 network analyzer and displayed using the Bode Analyzer Suite software. In this regard, 801 logarithmically spaced frequency points in the range $10 \mathrm{~Hz}$ to $100 \mathrm{kHz}$ were considered. The level of the testing harmonic signal was set to $V_{\mathrm{PP}}=1 \mathrm{~V}$.

The receiver bandwidth of the analyzer was fixed at $100 \mathrm{~Hz}$. The time-domain behaviors of the practical filters were observed on Agilent InfiniiVision DSO-X 2002A digital storage oscilloscope. The voltage $1 V_{\mathrm{PP}}$ (default value) was applied to the filter circuit from the Agilent 33521A function/arbitrary waveform generator during measurements of time-domain responses. Figure 9 presents the photograph of the hardware set-up used to experimentally validate the performance of the proposed filters with the display demonstrating the frequency responses for the BPPLF as a test case.

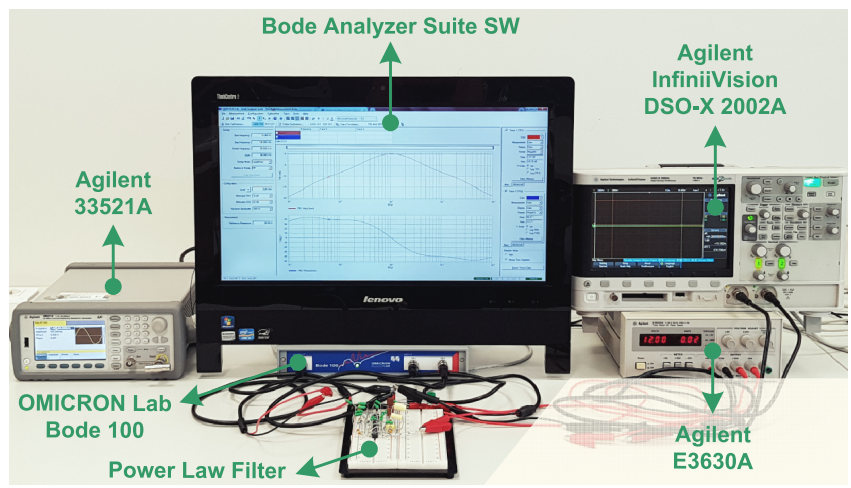

Figure 9. Photograph of the experimental set-up.

\subsection{Measurement Results for the PLFs}

The experimentally obtained magnitude and phase characteristics for the proposed LPPLF, HPPLF, BPPLF, and BSPLF are compared with the theoretical ones in Figure 10a-d, respectively. All the cases achieve excellent agreement with the ideal responses. The MARE values (determined using $L=801$ ) attained for the practical PLFs exhibiting the LP, HP, BP, and BS behaviors are $0.1006,0.9668,0.1307$, and 1.0031 , respectively.

The time-domain responses of the proposed LPPLF and HPPLF measured at the half-power frequency $\left(f_{\mathrm{H}}\right)$ of $1.11 \mathrm{kHz}$ and $738 \mathrm{~Hz}$, respectively, are shown in Figure 11a,b, respectively. The peak-to-peak output voltage ( $\left.V_{\text {OUT(PP) }}\right)$ obtained for the LPPLF and HPPLF at $f_{\mathrm{H}}$ are $700 \mathrm{mV}$ and $680 \mathrm{mV}$, respectively. Figure $12 \mathrm{a}-\mathrm{c}$ show the three timedomain input-output waveforms for the BPPLF (namely, BPPLF-a, BPPLF-b, and BPPLF-c) when the input signal is applied at the center frequency $\left(f_{0}=1.066 \mathrm{kHz}\right)$, low half-power frequency $\left(f_{\mathrm{H}, \mathrm{low}}=353.9 \mathrm{~Hz}\right)$, and high half-power frequency $\left(f_{\mathrm{H}, \mathrm{high}}=3.214 \mathrm{kHz}\right)$, respectively.

The corresponding values of $V_{\text {OUT(PP) }}$ are attained as $1.01 \mathrm{~V}, 710 \mathrm{mV}$, and $720 \mathrm{mV}$, respectively. In Figure 13a,b, the two transient responses for the BSPLF (namely, BSPLF-a, and BSPLF-b) at the input signal frequencies of $f_{\mathrm{H}, \mathrm{low}}(614 \mathrm{~Hz})$ and $f_{\mathrm{H}, \mathrm{high}}(1.47 \mathrm{kHz})$, respectively, are presented. Both cases yield $710 \mathrm{mV}$ for $V_{\text {OUT(PP) }}$. The values for $f_{0}, f_{\mathrm{H}}$, $f_{\mathrm{H} \text {,low }}$ and $f_{\mathrm{H} \text {,high }}$ are considered with respect to the experimental measurements.

The Fourier spectrums of the measured output signals displayed up to the sixth harmonic above -95 dBV for the LPPLF, HPPLF, BPPLF-a, BPPLF-b, BPPLF-c, BSPLF-a, and BSPLF-b are shown in Figure $14 \mathrm{a}-\mathrm{g}$, respectively. The Spurious-Free Dynamic Range (SFDR), expressed in $\mathrm{dBc}$, for the seven cases is respectively obtained as $60.35,59.77,62.77$, 57.23, 57.81, 58.20, and 57.62. The Total Harmonic Distortion (THD), evaluated from the plotted harmonics, is obtained as $0.17 \%, 0.15 \%, 0.07 \%, 0.16 \%, 0.16 \%, 0.15 \%$, and $0.19 \%$. 

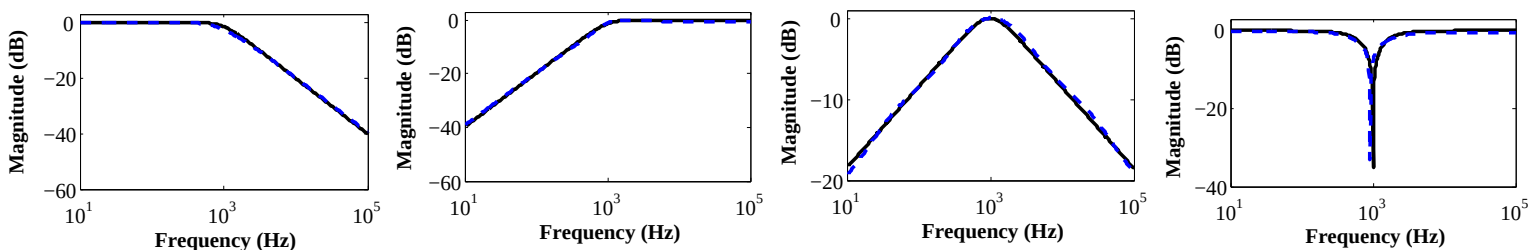

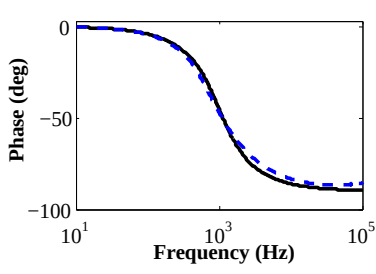

(a)

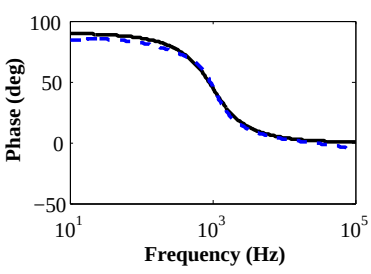

(b)

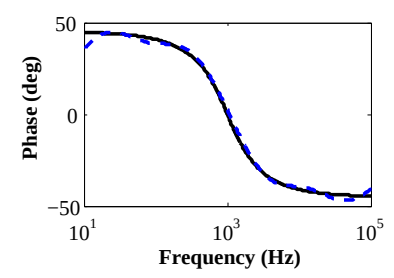

(c)

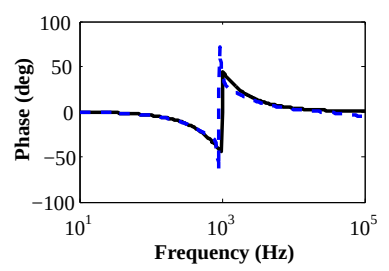

(d)

Figure 10. Comparisons between the theoretical (solid black) and experimentally (dashed blue) obtained (a) LP, (b) HP, (c) BP, and (d) BS filter frequency responses of the PLFs $(\alpha=0.5)$.

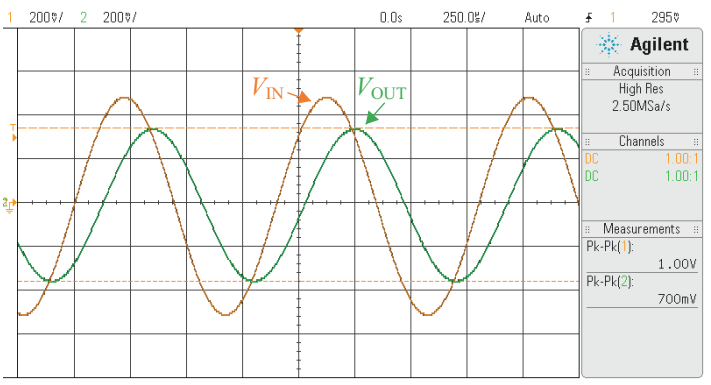

(a)

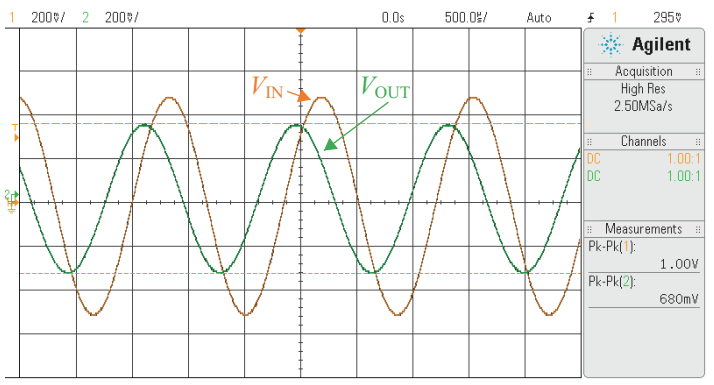

(b)

Figure 11. Input-output waveforms observed in oscilloscope for the proposed (a) LPPLF $(\alpha=0.5)$ with an input frequency of $f_{\mathrm{H}}=1.11 \mathrm{kHz},(\mathbf{b}) \mathrm{HPPLF}(\alpha=0.5)$ with an input frequency of $f_{\mathrm{H}}=738 \mathrm{~Hz}$.

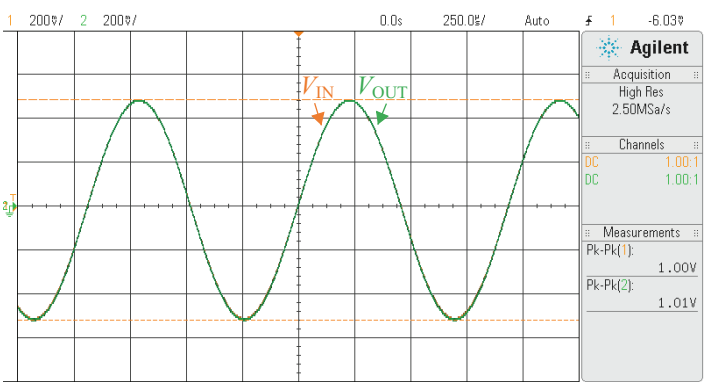

(a)

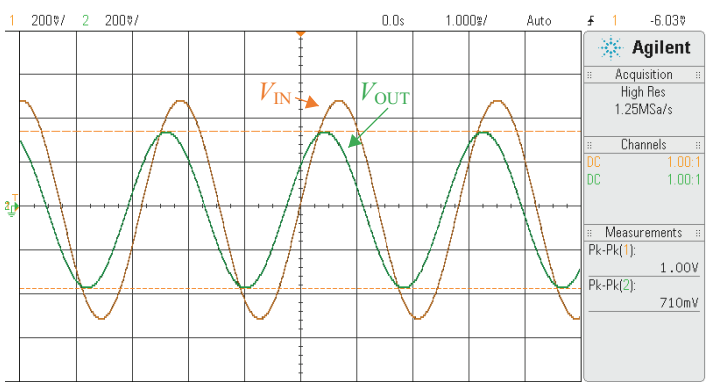

(b)

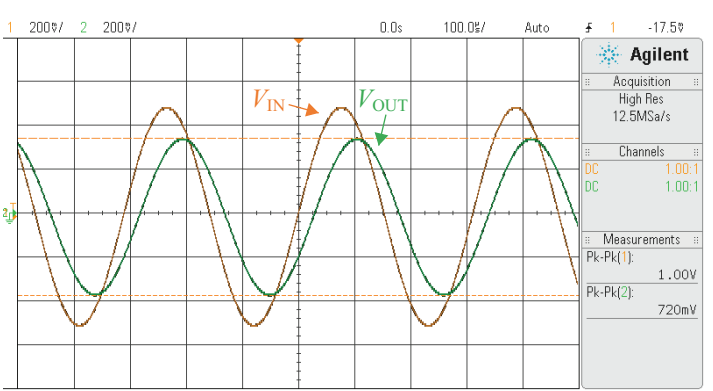

(c)

Figure 12. Input-output waveforms observed in oscilloscope for the proposed BPPLF $(\alpha=0.5)$ with an input frequency of (a) $f_{0}=1.066 \mathrm{kHz},(\mathbf{b}) f_{\mathrm{H}, \mathrm{low}}=353.9 \mathrm{~Hz}$, and (c) $f_{\mathrm{H} \text {,high }}=3.214 \mathrm{kHz}$. 


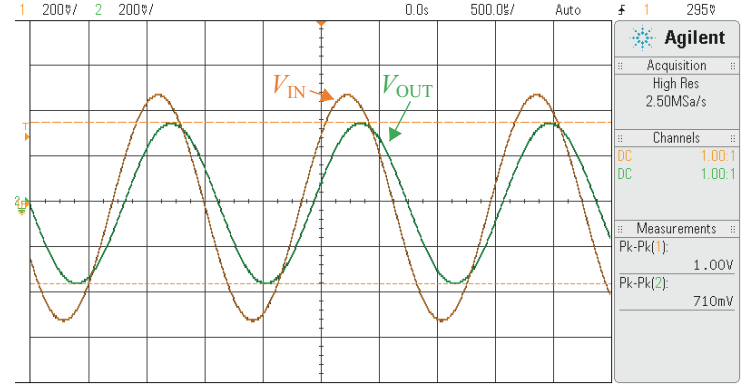

(a)

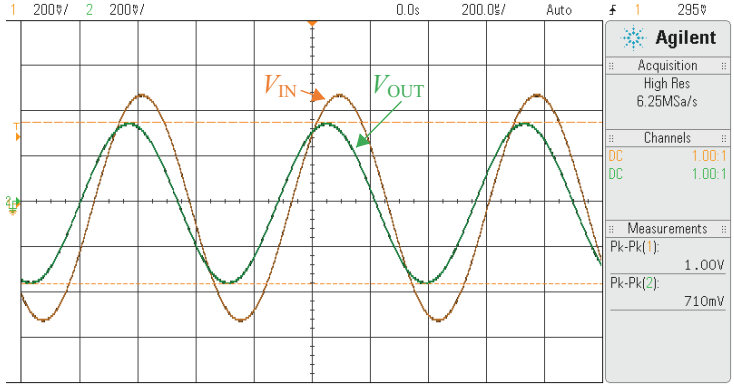

(b)

Figure 13. Input-output waveforms observed in oscilloscope for the proposed BSPLF $(\alpha=0.5)$ with an input frequency of (a) $f_{\mathrm{H}, \mathrm{low}}=614 \mathrm{~Hz}$ and (b) $f_{\mathrm{H} \text {,high }}=1.47 \mathrm{kHz}$.

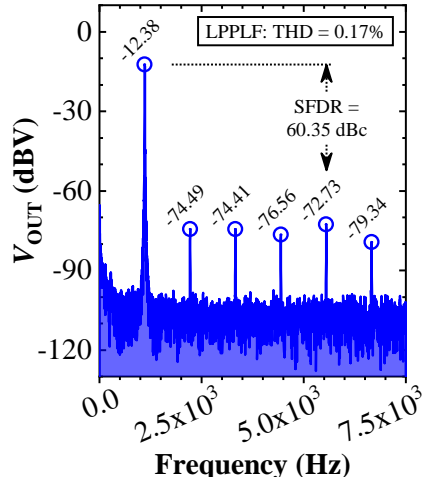

(a)

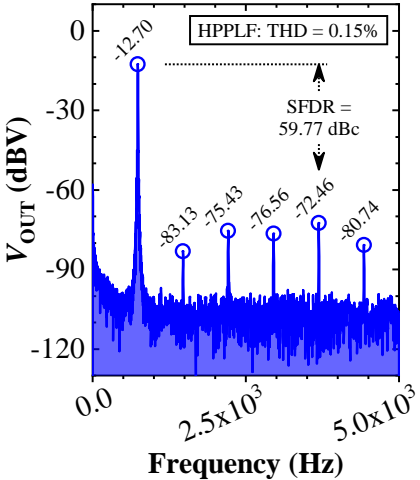

(b)

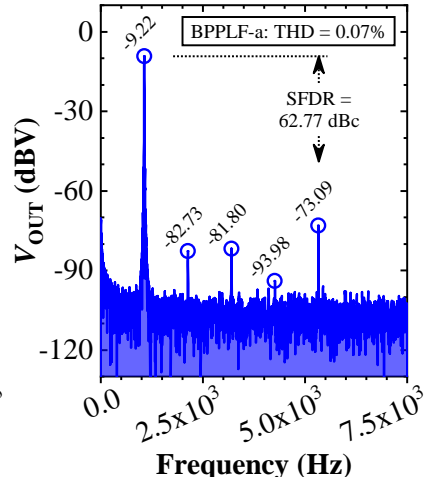

(c)

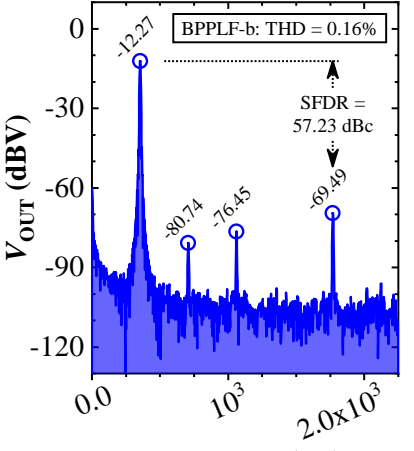

Frequency (Hz)

(d)

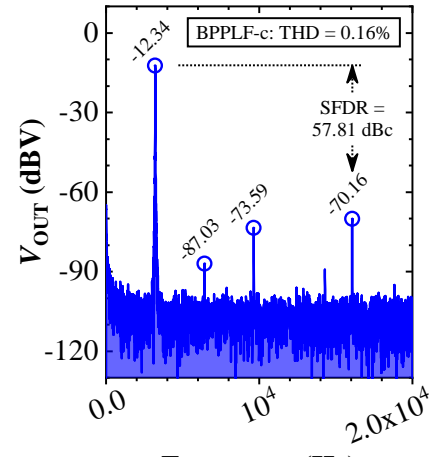

Frequency $(\mathrm{Hz})$

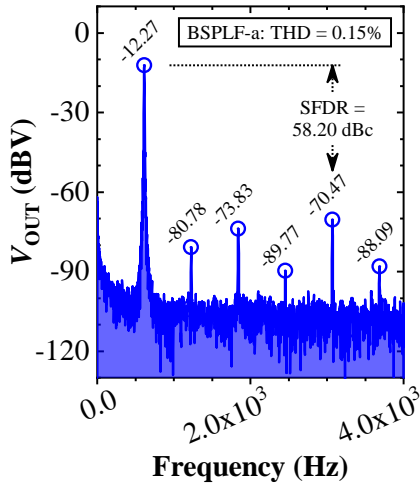

(f)

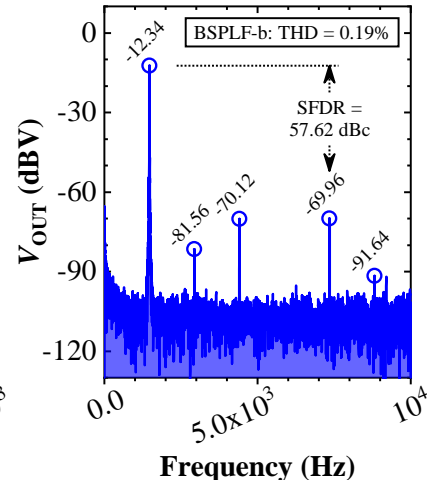

(g)

Figure 14. FFT spectrums (experimental) of the proposed filters $(\alpha=0.5)$ pertaining to the (a) LPPLF, (b) HPPLF, (c) BPPLF-a, (d) BPPLF-b, (e) BPPLF-c, (f) BSPLF-a, and (g) BSPLF-b.

\subsection{Measurement Results for the IPLFs}

Comparisons between the theoretical and experimental magnitude and phase responses achieved for the proposed ILPPLF, IHPPLF, IBPPLF, and IBSPLF are presented in Figure 15a-d, respectively. The magnitude characteristics for all the cases demonstrate good agreement with the theoretical ones whereas the phase behavior deviates as the operating frequency approaches towards $100 \mathrm{kHz}$. The practical IPLFs with LP, HP, BP, and BS responses attain the MARE values of $0.2441,6.8457,0.2221$, and 3.6490, respectively. 

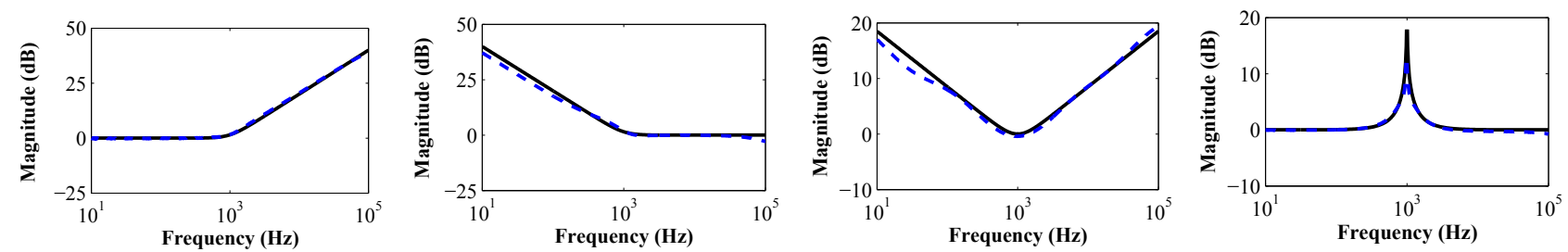

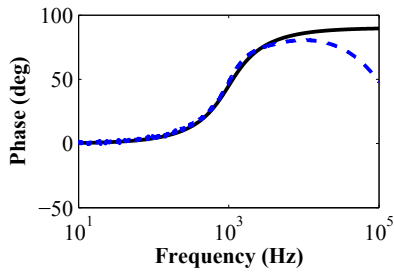

(a)

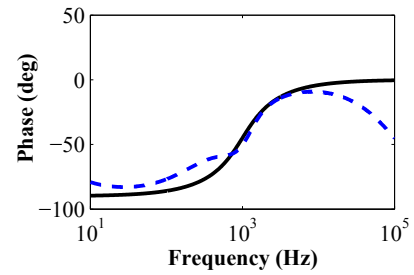

(b)

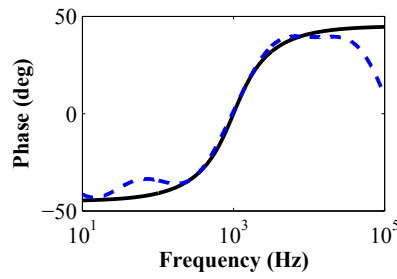

(c)

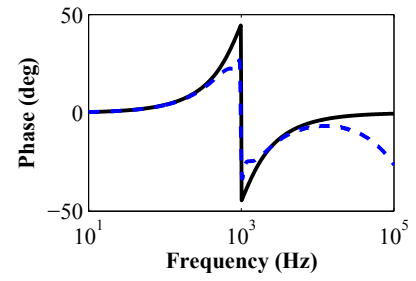

(d)

Figure 15. Comparisons between the theoretical (solid black) and experimentally (dashed blue) obtained (a) LP, (b) HP, (c) BP, and (d) BS filter frequency responses of the IPLFs $(\alpha=0.5)$.

Figure 16a,b show the time-domain input-output waveforms of the practical ILPPLF and IHPPLF measured at the input frequency of $f_{\mathrm{H}}=1.212 \mathrm{kHz}$ and $887.8 \mathrm{~Hz}$, respectively. Measurements reveal that $V_{\mathrm{OUT}}(\mathrm{PP})$ of $1.259 \mathrm{~V}$ and $1.421 \mathrm{~V}$ are, respectively, obtained for the ILPPLF and the IHPPLF. The time-domain responses for the IBPPLF (i.e., IBPPLF-a, IBPPLF-b, and IBPPLF-c) at the input frequencies of $f_{0}=967 \mathrm{~Hz}, f_{\mathrm{H} \text {,low }}=330.3 \mathrm{~Hz}$, and $f_{\mathrm{H} \text {,high }}=2.919 \mathrm{kHz}$ are presented in Figure 17a-c. The values of $V_{\mathrm{OUT}(\mathrm{PP})}$ achieved for these three cases are $0.966 \mathrm{~V}, 1.374 \mathrm{~V}$, and $1.355 \mathrm{~V}$, respectively. The input-output plots for the IBSPLF (i.e., IBSPLF-a and IBSPLF-b) at the input frequencies of $f_{\mathrm{H} \text {,low }}=650.3 \mathrm{~Hz}$ and $f_{\mathrm{H}, \text { high }}=1.482 \mathrm{kHz}$ are shown in Figure 18a,b, respectively. The measured values of $V_{\mathrm{OUT}(\mathrm{PP})}$ at these two frequencies are obtained as $1.438 \mathrm{~V}$ and $1.426 \mathrm{~V}$, respectively.

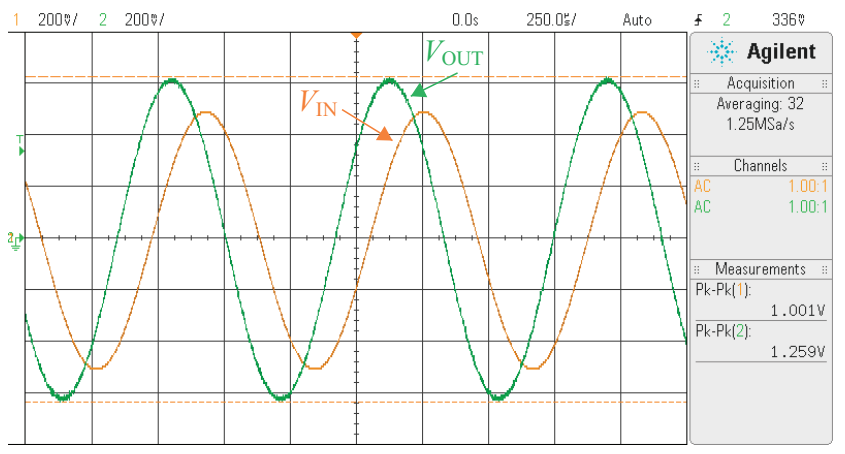

(a)

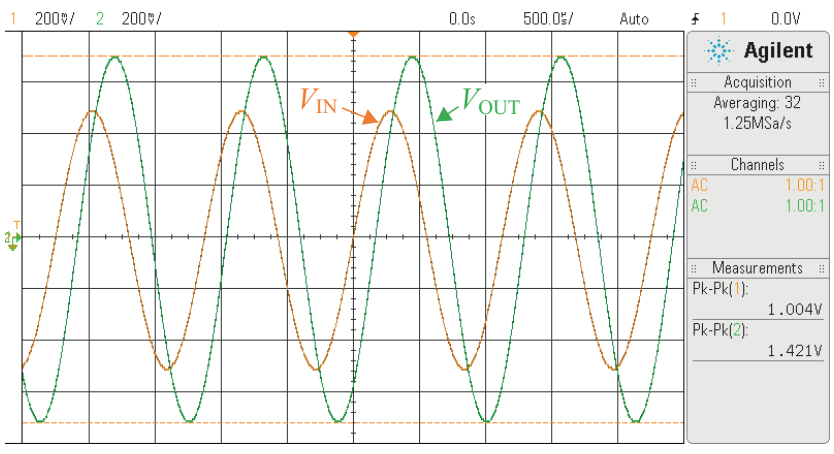

(b)

Figure 16. Input-output waveforms observed in oscilloscope for the proposed (a) ILPPLF $(\alpha=0.5)$ with an input frequency of $f_{\mathrm{H}}=1.212 \mathrm{kHz},(\mathbf{b}) \operatorname{IHPPLF}(\alpha=0.5)$ with an input frequency of $f_{\mathrm{H}}=887.8 \mathrm{~Hz}$.

Figure 19a-g present the FFT plots of the measured output responses for the proposed ILPPLF, IHPPLF, IBPPLF-a, IBPPLF-b, IBPPLF-c, IBSPLF-a, and IBSPLF-b. The SFDR $(\mathrm{dBc})$ attained for these designs is $63.44,54.72,57.41,58.30,58.25,65.39$, and 61.61; the corresponding THD values are $0.10 \%, 0.21 \%, 0.17 \%, 0.15 \%, 0.15 \%, 0.07 \%$, and $0.11 \%$. 


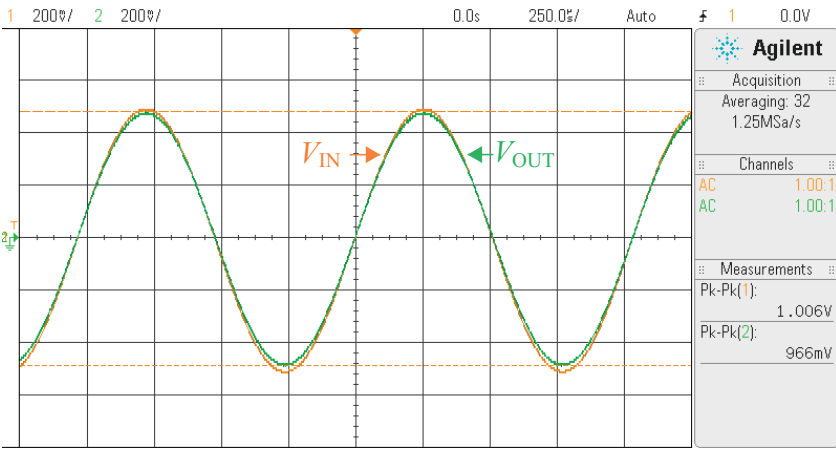

(a)

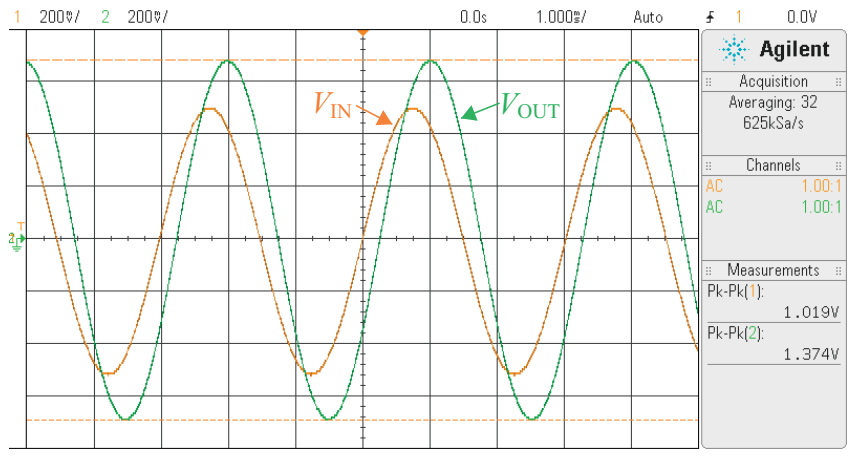

(b)

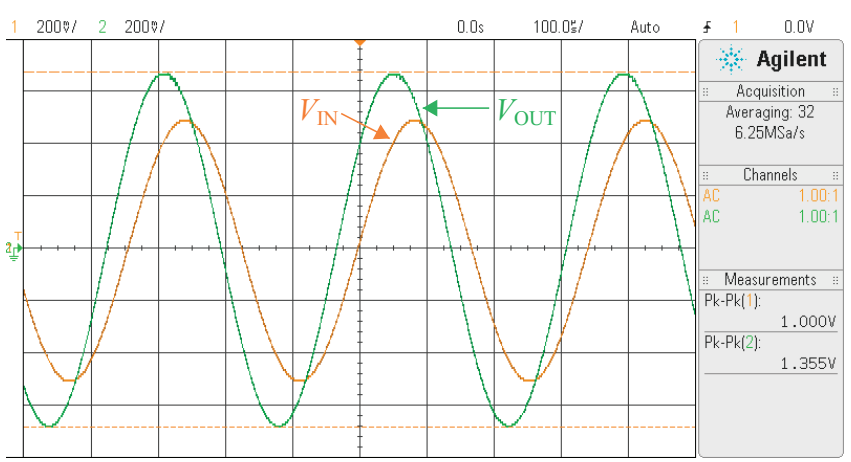

(c)

Figure 17. Input-output waveforms observed in oscilloscope for the proposed IBPPLF ( $\alpha=0.5)$ with an input frequency of (a) $f_{0}=967 \mathrm{~Hz}$, (b) $f_{\mathrm{H}, \text { low }}=330.3 \mathrm{~Hz}$, and (c) $f_{\mathrm{H}, \text { high }}=2.919 \mathrm{kHz}$.

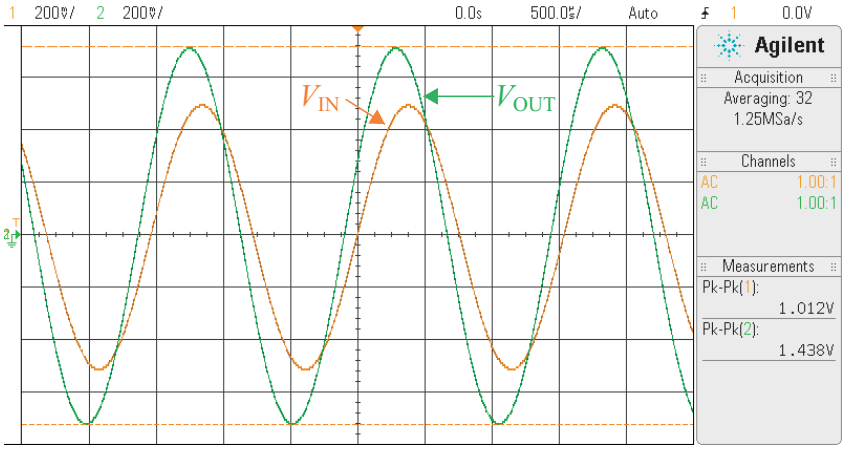

(a)

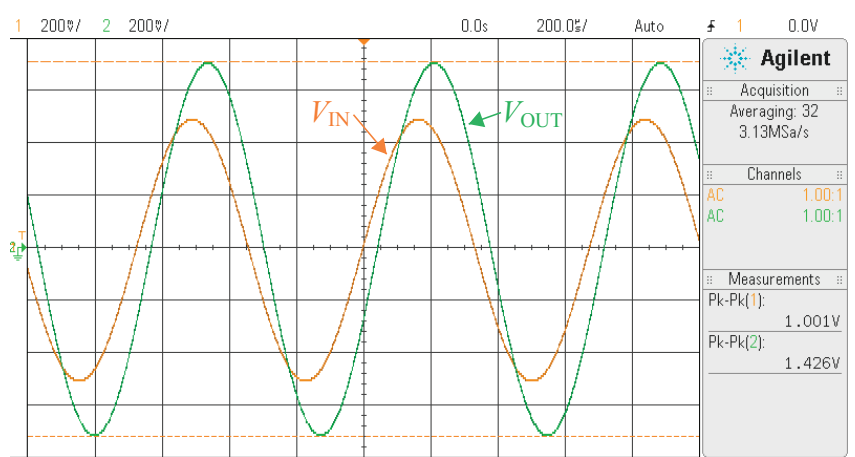

(b)

Figure 18. Input-output waveforms observed in oscilloscope for the proposed IBSPLF $(\alpha=0.5)$ with an input frequency of (a) $f_{\mathrm{H}, \mathrm{low}}=650.3 \mathrm{~Hz}$ and $(\mathbf{b}) f_{\mathrm{H}, \text { high }}=1.482 \mathrm{kHz}$. 


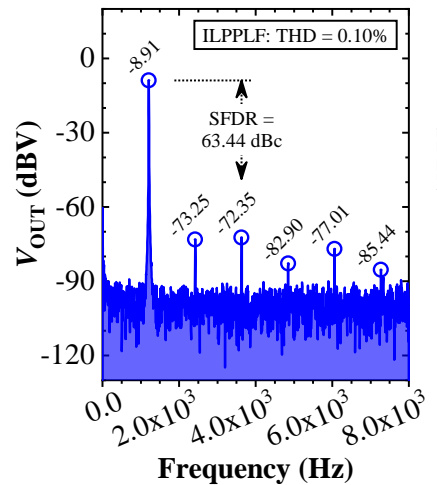

(a)

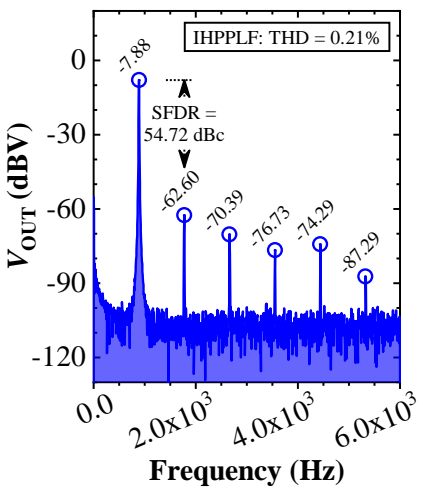

(b)

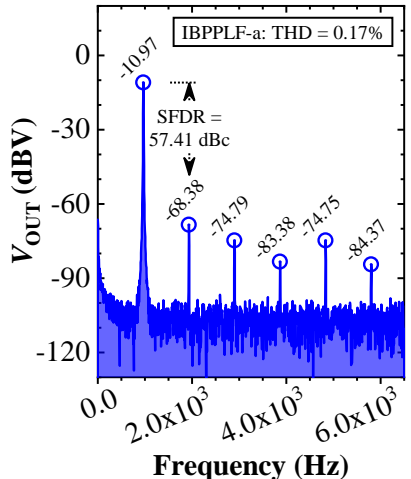

(c)

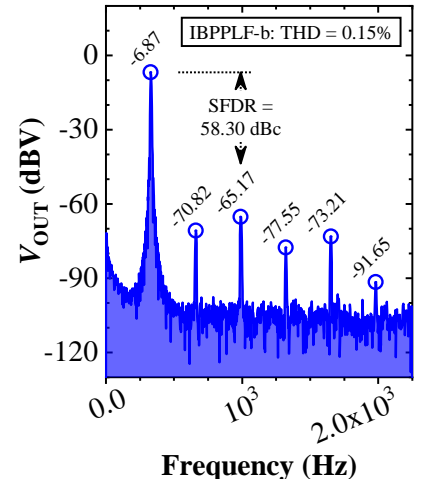

(d)

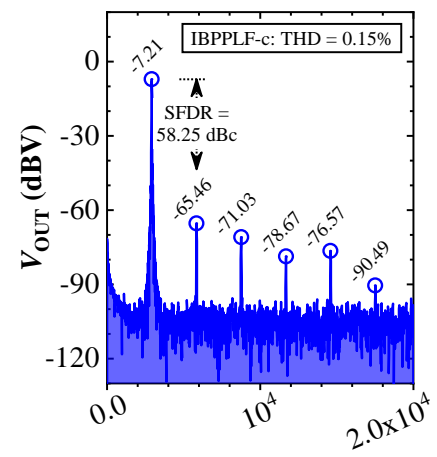

Frequency $(\mathbf{H z})$

(e)

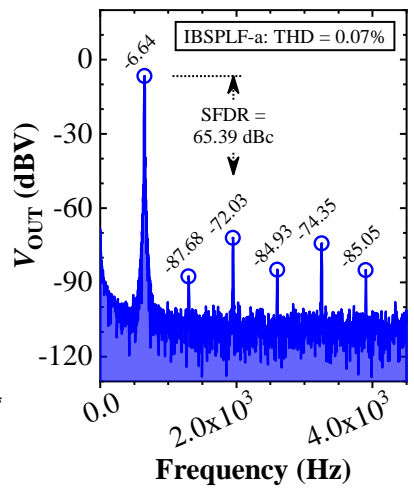

(f)

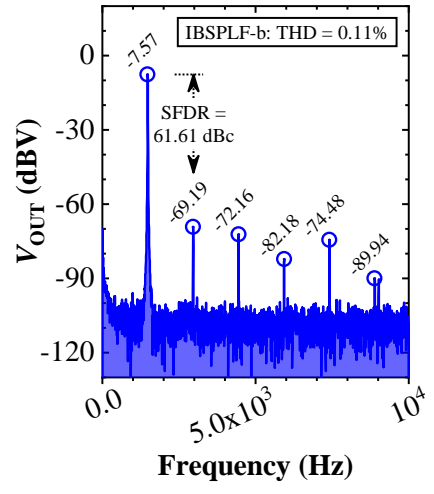

(g)

Figure 19. FFT spectrums (experimental) of the proposed inverse filters $(\alpha=0.5)$ pertaining to the (a) ILPPLF, (b) IHPPLF, (c) IBPPLF-a, (d) IBPPLF-b, (e) IBPPLF-c, (f) IBSPLF-a, and (g) IBSPLF-b.

\section{Conclusions}

In this paper, we presented the optimal and stable rational approximation of the PLFs and their inverse functions. Design examples for the LP, HP, BP, and BS-type PLFs with $\alpha=\{0.3,0.5,0.7\}$ and three different objective functions were presented. Statistical performance comparisons and Wilcoxon rank-sum test results revealed that no single objective function attained the best accuracy and solution quality consistency for all types of PLFs. Comparisons with published literature highlighted the improved accuracy for all the proposed PLFs. The drawback of obtaining unstable ILPPLF and IHPPLF for several design orders based on the reported S-K method was circumvented here through the incorporation of design constraints.

Since the PLF/IPLF design is an offline procedure, the inferior computational time of the proposed technique may be waived in favor of attaining the previously-mentioned benefits. CFOAs employed as active elements were used to practically realize the proposed PLFs and IPLFs for all four response types with $\alpha=0.5$. The experimental results exemplified an excellent agreement in the magnitude and phase responses with the ideal PLFs. The magnitude behavior for the IPLFs also attained proximity with the theoretical anticipations. For all measurements, the THD remained lower than $0.2 \%$, and the SFDR exceeded $57.23 \mathrm{dBc}$ for the PLFs. In the case of IPLFs, the THD and SFDR values were equal or smaller than $0.21 \%$ and larger than $54.72 \mathrm{dBc}$, respectively. 
Author Contributions: Conceptualization, S.M., N.H. and D.K.; methodology, S.M.; software, S.M.; validation, S.M., N.H. and D.K.; formal analysis, S.M.; investigation, S.M.; resources, N.H.; data curation, S.M.; writing—original draft preparation, S.M. and N.H.; writing—review and editing, S.M., N.H. and D.K.; visualization, S.M. and N.H.; supervision, N.H.; project administration, N.H.; funding acquisition, N.H. All authors have read and agreed to the published version of the manuscript.

Funding: The research results described in this paper are supported by The Czech Science Foundation, project No. 19-24585S.

Institutional Review Board Statement: Not applicable.

Informed Consent Statement: Not applicable.

Data Availability Statement: The data presented in this study are available on request from the authors.

Conflicts of Interest: The authors declare no conflict of interest.

\section{Appendix A}

See Table A1.

Table A1. Optimal coefficients of the designed PLFs based on different objective functions $\left(f_{k}\right)$.

\begin{tabular}{|c|c|c|c|}
\hline Filter & $f_{k}$ & $\alpha$ & $X$ \\
\hline \multirow{9}{*}{ LPPLF } & \multirow{3}{*}{$f_{1}$} & 0.3 & {$\left[\begin{array}{lllllllll}0.0237 & 6.5086 & 157.6053 & 608.9508 & 435.0749 & 55.8440 & 461.1371 & 792.3060 & 435.0843\end{array}\right]$} \\
\hline & & 0.5 & {$\left[\begin{array}{lllllllll}0.0000 & 1.0000 & 3.3454 & 3.9298 & 1.6952 & 4.0523 & 6.5467 & 5.1288 & 1.6952\end{array}\right]$} \\
\hline & & 0.7 & 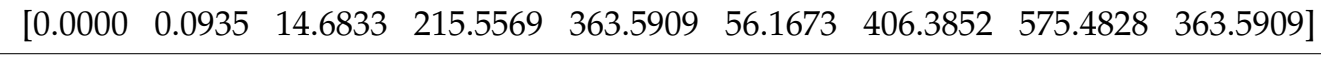 \\
\hline & \multirow{3}{*}{$f_{2}$} & 0.3 & {$\left[\begin{array}{lllllllll}0.0251 & 6.1852 & 130.3929 & 454.1981 & 337.5340 & 48.9649 & 357.4187 & 596.5829 & 337.5048\end{array}\right]$} \\
\hline & & 0.5 & {$\left[\begin{array}{lllllllll}0.0000 & 1.0000 & 4.3404 & 5.8369 & 2.7806 & 5.0470 & 9.1598 & 7.8036 & 2.7806\end{array}\right]$} \\
\hline & & 0.7 & {$\left[\begin{array}{lllllllll}0.0000 & 0.0923 & 14.9358 & 225.8841 & 382.2588 & 57.9809 & 426.5128 & 604.2660 & 382.2596\end{array}\right]$} \\
\hline & \multirow{3}{*}{$f_{3}$} & 0.3 & {$\left[\begin{array}{lllllllll}0.0226 & 6.7236 & 168.2873 & 653.3916 & 495.0099 & 59.0935 & 493.5963 & 863.3283 & 495.0150\end{array}\right]$} \\
\hline & & 0.5 & 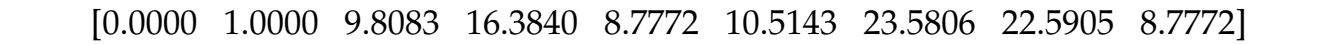 \\
\hline & & 0.7 & {$\left[\begin{array}{lllllllll}0.0000 & 0.0913 & 15.5822 & 238.8673 & 406.6527 & 60.8165 & 451.6448 & 641.4255 & 406.6529\end{array}\right]$} \\
\hline \multirow{9}{*}{ HPPLF } & \multirow{3}{*}{$f_{1}$} & 0.3 & {$\left[\begin{array}{lllllllll}1.0002 & 7.5918 & 14.8771 & 1.8950 & 0.0121 & 8.0206 & 18.1103 & 9.0732 & 0.3853\end{array}\right]$} \\
\hline & & 0.5 & {$\left[\begin{array}{lllllllll}1.0000 & 9.3030 & 14.9498 & 7.7159 & 0.0000 & 10.0097 & 21.7838 & 20.4089 & 7.7158\end{array}\right]$} \\
\hline & & 0.7 & {$\left[\begin{array}{lllllllll}1.0000 & 0.5868 & 0.038258 & 0.000224 & 0.0000 & 1.5767 & 1.1100 & 0.1493 & 0.0024555\end{array}\right]$} \\
\hline & \multirow{3}{*}{$f_{2}$} & 0.3 & {$\left[\begin{array}{lllllllll}1.0001 & 12.8022 & 22.9435 & 3.1493 & 0.0213 & 13.2325 & 28.3618 & 14.3874 & 0.6643\end{array}\right]$} \\
\hline & & 0.5 & {$\left[\begin{array}{lllllllll}1.0000 & 19.5428 & 32.3707 & 16.4524 & 0.0000 & 20.2498 & 46.4427 & 44.0274 & 16.4512\end{array}\right]$} \\
\hline & & 0.7 & {$\left[\begin{array}{lllllllll}0.9995 & 9.9045 & 2.9823 & 0.0395 & 0.0000 & 10.8723 & 13.5286 & 7.2042 & 0.3404\end{array}\right]$} \\
\hline & \multirow{3}{*}{$f_{3}$} & 0.3 & {$\left[\begin{array}{lllllllll}1.0000 & 1.3285 & 0.3407 & 0.01354 & 0.0000453 & 1.7526 & 1.0021 & 0.1194 & 0.00201\end{array}\right]$} \\
\hline & & 0.5 & {$\left[\begin{array}{lllllllll}1.0000 & 2.6111 & 2.5477 & 0.9238 & 0.0000 & 3.3182 & 4.6441 & 3.2008 & 0.9238\end{array}\right]$} \\
\hline & & 0.7 & {$\left[\begin{array}{lllllllll}1.0000 & 6.2426 & 2.1947 & 0.0444 & 0.0000 & 7.2319 & 8.8913 & 4.9099 & 0.2952\end{array}\right]$} \\
\hline \multirow{9}{*}{ BPPLF } & \multirow{3}{*}{$f_{1}$} & 0.3 & {$\left[\begin{array}{lllllllll}0.2099 & 18.7044 & 113.0789 & 18.4473 & 0.2033 & 38.0356 & 117.7061 & 37.7091 & 0.9723\end{array}\right]$} \\
\hline & & 0.5 & 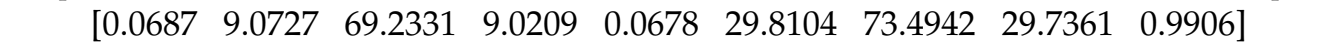 \\
\hline & & 0.7 & {$\left[\begin{array}{lllllllll}0.0194 & 4.3195 & 40.6182 & 4.2579 & 0.0189 & 22.5306 & 43.6451 & 22.4438 & 0.9807\end{array}\right]$} \\
\hline & \multirow{3}{*}{$f_{2}$} & 0.3 & {$\left[\begin{array}{lllllllll}0.2127 & 18.0508 & 102.8481 & 18.0055 & 0.2118 & 36.1575 & 106.9896 & 36.1009 & 0.9960\end{array}\right]$} \\
\hline & & 0.5 & {$\left[\begin{array}{lllllllll}0.0703 & 8.6453 & 59.6221 & 8.6040 & 0.0697 & 27.2035 & 63.2085 & 27.1331 & 0.9931\end{array}\right]$} \\
\hline & & 0.7 & {$\left[\begin{array}{lllllllll}0.0200 & 4.1789 & 35.4722 & 4.1789 & 0.0200 & 20.5126 & 38.2202 & 20.5126 & 1.0000\end{array}\right]$} \\
\hline & \multirow{3}{*}{$f_{3}$} & 0.3 & {$\left[\begin{array}{lllllllll}0.2176 & 17.2313 & 87.4857 & 17.2161 & 0.2167 & 33.5267 & 89.6188 & 33.5101 & 0.9971]\end{array}\right.$} \\
\hline & & 0.5 & {$\left[\begin{array}{lllllllll}0.0727 & 8.6573 & 56.5588 & 8.6576 & 0.0727 & 26.6767 & 58.9923 & 26.6771 & 1.0001\end{array}\right]$} \\
\hline & & 0.7 & {$\left[\begin{array}{lllllllll}0.0202 & 4.2911 & 36.7490 & 4.2911 & 0.0202 & 21.2939 & 39.0462 & 21.2940 & 1.0000]\end{array}\right]$} \\
\hline
\end{tabular}


Table A1. Cont.

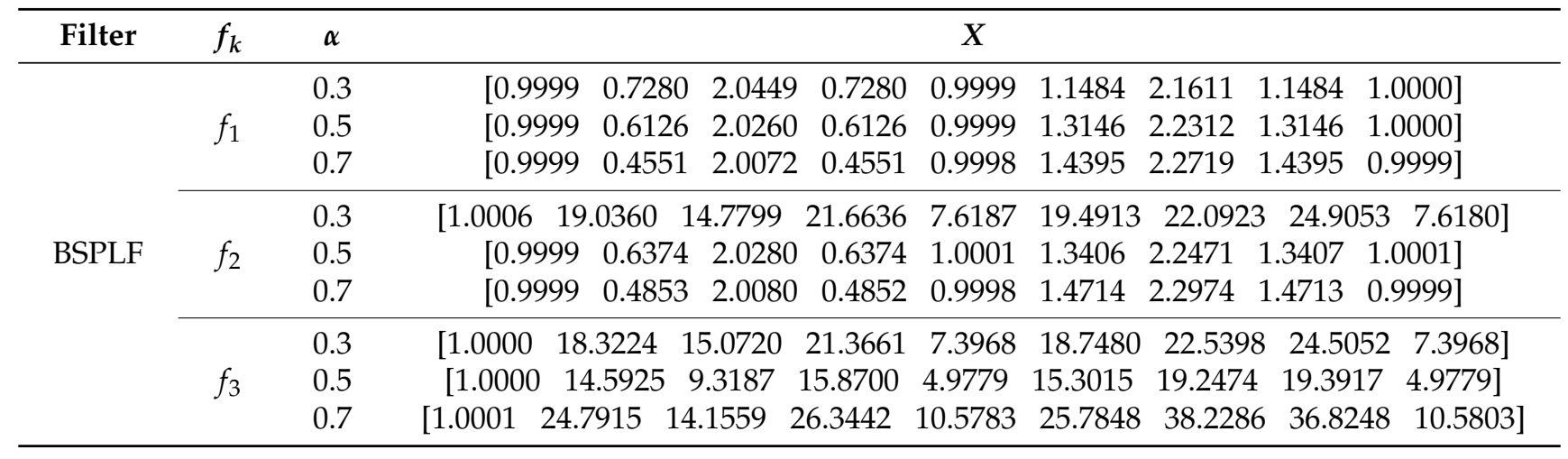

\section{Abbreviations and Symbols}

The following abbreviations and symbols are used in this manuscript:

\begin{tabular}{|c|c|}
\hline BP & Band-Pass \\
\hline BPPLF & Band-Pass Power Law Filter \\
\hline BS & Band-Stop \\
\hline BSPLF & Band-Stop Power Law Filter \\
\hline CFOA & Current Feedback Operational Amplifier \\
\hline FFT & Fast Fourier Transform \\
\hline $\mathrm{FO}$ & Fractional-Order \\
\hline $\mathrm{HP}$ & High-Pass \\
\hline HPPLF & High-Pass Power Law Filter \\
\hline IBPPLF & Inverse Band-Pass Power Law Filter \\
\hline IBSPLF & Inverse Band-Stop Power Law Filter \\
\hline IHPPLF & Inverse High-Pass Power Law Filter \\
\hline ILPPLF & Inverse Low-Pass Power Law Filter \\
\hline IPLF & Inverse Power Law Filter \\
\hline LP & Low-Pass \\
\hline LPPLF & Low-Pass Power Law Filter \\
\hline MARE & Mean Absolute Relative Error \\
\hline PLF & Power Law Filter \\
\hline SD & Standard Deviation \\
\hline SFDR & Spurious-Free Dynamic Range \\
\hline THD & Total Harmonic Distortion \\
\hline$a_{k}$ & Numerator coefficients of the proposed approximant \\
\hline$\alpha$ & Fractional order \\
\hline$b_{k}$ & Denominator coefficients of the proposed approximant \\
\hline$\Delta_{N}$ & Hurwitz determinants \\
\hline$f_{\mathrm{H}}$ & Half-power frequency \\
\hline$f_{\mathrm{H}, \mathrm{high}}$ & High half-power frequency \\
\hline$f_{\mathrm{H}, \mathrm{low}}$ & Low half-power frequency \\
\hline $\mathrm{H}$ & Decision index for Wilcoxon rank-sum test \\
\hline iter $_{\mathrm{m}}$ & Maximum count of loop \\
\hline$L$ & Total number of sampled data points \\
\hline$N$ & Order of the proposed approximant \\
\hline$\omega_{\max }$ & Upper bound of bandwidth \\
\hline$\omega_{\min }$ & Lower bound of bandwidth \\
\hline$\omega_{0}$ & Pole frequency \\
\hline$\omega$ & Angular frequency \\
\hline$p$-val & $p$-value of Wilcoxon rank-sum test \\
\hline$Q$ & Quality factor \\
\hline$s^{\alpha}$ & Fractional-order Laplacian operator \\
\hline$X$ & Vector of design variables \\
\hline$X_{\text {best }}$ & Best optimal vector of design variables \\
\hline
\end{tabular}




\section{References}

1. Monje, C.A.; Chen, Y.; Vinagre, B.M.; Xue, D.; Feliu-Batlle, V. Fractional-Order Systems and Controls: Fundamentals and Applications; Springer Science \& Business Media: New York, NY, USA, 2010.

2. Petráš, I. Fractional-Order Nonlinear Systems: Modeling, Analysis and Simulation; Springer Science \& Business Media: New York, NY, USA, 2011.

3. Cafagna, D. Fractional calculus: A mathematical tool from the past for present engineers [Past and present]. IEEE Ind. Electron. Mag. 2007, 1, 35-40. [CrossRef]

4. Tavazoei, M.S.; Tavakoli-Kakhki, M.; Bizzarri, F. Nonlinear fractional-order circuits and systems: Motivation, a brief overview, and some future directions. IEEE Open J. Circuits Syst. 2020, 1, 220-232. [CrossRef]

5. Yazgac, B.G.; Kirci, M. Fractional differential equation-based instantaneous frequency estimation for signal reconstruction. Fractal Fract. 2021, 5, 83. [CrossRef]

6. Muresan, C.I.; Birs, I.R.; Dulf, E.H.; Copot, D.; Miclea, L. A review of recent advances in fractional-order sensing and filtering techniques. Sensors 2021, 21, 5920. [CrossRef] [PubMed]

7. Jain, M.; Rani, A.; Pachauri, N.; Singh, V.; Mittal, A.P. Design of fractional order 2-DOF PI controller for real-time control of heat flow experiment. Eng. Sci. Technol. 2019, 22, 215-228. [CrossRef]

8. Freeborn, T.J.; Critcher, S. Cole-impedance model representations of right-side segmental arm, leg, and full-body bioimpedances of healthy adults: Comparison of fractional-order. Fractal Fract. 2021, 5, 13. [CrossRef]

9. Elwakil, A.S. Fractional-order circuits and systems: An emerging interdisciplinary research area. IEEE Circuits Syst. Mag. 2010, 10, 40-50. [CrossRef]

10. Radwan, A.G.; Soliman, A.M.; Elwakil, A.S. First-order filters generalized to the fractional domain. J. Circuits Syst. Comput. 2008, 17, 55-66. [CrossRef]

11. Wang, S.F.; Chen, H.P.; Ku, Y.; Lin, Y.C. Versatile tunable voltage-mode biquadratic filter and its application in quadrature oscillator. Sensors 2019, 19, 2349. [CrossRef]

12. Krishna, B.T. Studies on fractional order differentiators and integrators: A survey. Signal Process. 2011, 91, 386-426. [CrossRef]

13. Oustaloup, A.; Levron, F.; Mathieu, B.; Nanot, F.M. Frequency-band complex noninteger differentiator: Characterization and synthesis. IEEE Trans. Circuits Syst. I Fundam. Theory Appl. 2000, 47, 25-39. [CrossRef]

14. El-Khazali, R. On the biquadratic approximation of fractional-order Laplacian operators. Analog Integr. Circuits Signal Process. 2015, 82, 503-517. [CrossRef]

15. AbdelAty, A.M.; Elwakil, A.S.; Radwan, A.G.; Psychalinos, C.; Maundy, B.J. Approximation of the fractional-order Laplacian $s^{\alpha}$ as a weighted sum of first-order high-pass filters. IEEE Trans. Circuits Syst. II Express Briefs 2018, 65, 1114-1118. [CrossRef]

16. Shah, Z.M.; Kathjoo, M.Y.; Khanday, F.A.; Biswas, K.; Psychalinos, C. A survey of single and multi-component fractional-order elements (FOEs) and their applications. Microelectron. J. 2019, 84, 9-25. [CrossRef]

17. Kartci, A.; Agambayev, A.; Herencsar, N.; Salama, K.N. Series-, parallel-, and inter-connection of solid-state arbitrary fractionalorder capacitors: Theoretical study and experimental verification. IEEE Access 2018, 6, 10933-10943. [CrossRef]

18. Zhang, L.; Kartci, A.; Elwakil, A.; Bagci, H.; Salama, K.N. Fractional-order inductor: Design, simulation, and implementation. IEEE Access 2021, 9, 73695-73702. [CrossRef]

19. Tsirimokou, G.; Kartci, A.; Koton, J.; Herencsar, N.; Psychalinos, C. Comparative study of discrete component realizations of fractional-order capacitor and inductor active emulators. J. Circuits Syst. Comput. 2018, 27, 1850170. [CrossRef]

20. Kartci, A.; Agambayev, A.; Farhat, M.; Herencsar, N.; Brancik, L.; Bagci, H.; Salama, K.N. Synthesis and optimization of fractional-order elements using a genetic algorithm. IEEE Access 2019, 7, 80233-80246. [CrossRef]

21. Adhikary, A.; Shil, A.; Biswas, K. Realization of foster structure-based ladder fractor with phase band specification. Circuits Syst. Signal Process. 2020, 39, 2272-2292. [CrossRef]

22. Koton, J.; Kubanek, D.; Dvorak, J.; Herencsar, N. On systematic design of fractional-order element series. Sensors 2021, 21, 1203. [CrossRef] [PubMed]

23. Ali, A.S.; Radwan, A.G.; Soliman, A.M. Fractional order Butterworth filter: Active and passive realizations. IEEE J. Emerg. Sel. Top. Circuits Syst. 2013, 3, 346-354. [CrossRef]

24. Freeborn, T.; Maundy, B.; Elwakil, A.S. Approximated fractional order Chebyshev lowpass filters. Math. Prob. Eng. 2015, 2015. [CrossRef]

25. Freeborn, T.J.; Elwakil, A.S.; Maundy, B. Approximated fractional-order inverse Chebyshev lowpass filters. Circuits Syst. Signal Process. 2016, 35, 1973-1982. [CrossRef]

26. Kubanek, D.; Freeborn, T.J.; Koton, J.; Dvorak, J. Validation of fractional-order lowpass elliptic responses of $(1+\alpha)$-order analog filters. Appl. Sci. 2018, 8, 2603. [CrossRef]

27. Mahata, S.; Saha, S.; Kar, R.; Mandal, D. Optimal integer-order rational approximation of $\alpha$ and $\alpha+\beta$ fractional-order generalised analogue filters. IET Signal Process. 2019, 13, 516-527. [CrossRef]

28. Freeborn, T.J.; Maundy, B.; Elwakil, A.S. Field programmable analogue array implementation of fractional step filters. IET Circuits Dev. Syst. 2010, 4, 514-524. [CrossRef]

29. Maundy, B.; Elwakil, A.S.; Freeborn, T.J. On the practical realization of higher-order filters with fractional stepping. Signal Process. 2011, 91, 484-491. [CrossRef] 
30. Psychalinos, C.; Tsirimokou, G.; Elwakil, A.S. Switched-capacitor fractional-step Butterworth filter design. Circuits Syst. Signal Process. 2016, 35, 1377-1393. [CrossRef]

31. Tsirimokou, G.; Psychalinos, C.; Elwakil, A.S. Fractional-order electronically controlled generalized filters. Int. J. Circuit Theory Appl. 2017, 45, 595-612. [CrossRef]

32. Mahata, S.; Kar, R.; Mandal, D. Optimal approximation of fractional-order systems with model validation using CFOA. IET Signal Process. 2019, 13, 787-797. [CrossRef]

33. Radwan, A.G.; Fouda, M.E. Optimization of fractional-order RLC filters. Circuits Syst. Signal Process. 2013, 32, 2097-2118. [CrossRef]

34. Hélie, T. Simulation of fractional-order low-pass filters. IEEE/ACM Trans. Audio Speech Lang. Process. 2014, $22,1636-1647$. [CrossRef]

35. Said, L.A.; Ismail, S.M.; Radwan, A.G.; Madian, A.H.; El-Yazeed, M.F.A.; Soliman, A.M. On the optimization of fractional order low-pass filters. Circuits Syst. Signal Process. 2016, 35, 2017-2039. [CrossRef]

36. Kubanek, D.; Freeborn, T. $(1+\alpha)$ fractional-order transfer functions to approximate low-pass magnitude responses with arbitrary quality factor. AEU-Int. J. Electron. Commun. 2018, 83, 570-578. [CrossRef]

37. Kubanek, D.; Freeborn, T.; Koton, J. Fractional-order band-pass filter design using fractional-characteristic specimen functions. Microelectron. J. 2019, 86, 77-86. [CrossRef]

38. Mahata, S.; Kar, R.; Mandal, D. Optimal approximation of asymmetric type fractional-order bandpass Butterworth filter using decomposition technique. Int. J. Circuit Theory Appl. 2020, 48, 1554-1560. [CrossRef]

39. Freeborn, T.J. Comparison of $(1+\alpha)$ fractional-order transfer functions to approximate lowpass Butterworth magnitude responses. Circuits Syst. Signal Process. 2016, 35, 1983-2002. [CrossRef]

40. Soni, A.; Sreejeth, N.; Saxena, V.; Gupta, M. Series optimized fractional order low pass Butterworth filter. Arab. J. Sci. Eng. 2020, 45, 1733-1747. [CrossRef]

41. Mahata, S.; Herencsar, N.; Kubanek, D. Optimal approximation of fractional-order Butterworth filter based on weighted sum of classical Butterworth filters. IEEE Access 2021, 9, 81097-81114. [CrossRef]

42. Mahata, S.; Kar, R.; Mandal, D. Optimal modelling of $(1+\alpha)$ order Butterworth filter under the CFE framework. Fractal Fract. 2020, 4, 55. [CrossRef]

43. Yousri, D.; AbdelAty, A.M.; Radwan, A.G.; Elwakil, A.S.; Psychalinos, C. Comprehensive comparison based on meta-heuristic algorithms for approximation of the fractional-order laplacian $\mathrm{s}^{\alpha}$ as a weighted sum of first-order high-pass filters. Microelectron. J. 2019, 87, 110-120. [CrossRef]

44. Adhikary, A.; Choudhary, S.; Sen, S. Optimal design for realizing a grounded fractional order inductor using GIC. IEEE Trans. Circuits Syst. I Regul. Pap. 2018, 65, 2411-2421. [CrossRef]

45. Soni, A.; Gupta, M. Analysis and design of optimized fractional order low-pass Bessel filter. J. Circuits Syst. Comput. 2021, 30, 2150035. [CrossRef]

46. Tugnait, J.K.; Li, T. Blind detection of asynchronous CDMA signals in multipath channels using code-constrained inverse filter criterion. IEEE Trans. Signal Process. 2001, 49, 1300-1309. [CrossRef]

47. Mouchtaris, A.; Reveliotis, P.; Kyriakakis, C. Inverse filter design for immersive audio rendering over loudspeakers. IEEE Trans. Multimed. 2000, 2, 77-87. [CrossRef]

48. Yuce, E.; Minaei, S. New CCII-based versatile structure for realizing PID controller and instrumentation amplifier. Microelectron. J. 2010, 41, 311-316. [CrossRef]

49. Ansari, R.; Kahn, D.; Macchi, M.J. Pitch modification of speech using a low-sensitivity inverse filter approach. IEEE Signal Process. Lett. 1998, 5, 60-62. [CrossRef]

50. Bhaskar, D.R.; Kumar, M.; Kumar, P. Fractional order inverse filters using operational amplifier. Analog Integr. Circuits Signal Process. 2018, 97, 149-158. [CrossRef]

51. Hamed, E.M.; Said, L.A.; Madian, A.H.; Radwan, A.G. On the approximations of CFOA-based fractional-order inverse filters. Circuits Syst. Signal Process. 2020, 39, 2-29. [CrossRef]

52. Khalil, N.A.; Said, L.A.; Radwan, A.G.; Soliman, A.M. Multifunction fractional inverse filter based on OTRA. In Proceedings of the 2019 Novel Intelligent and Leading Emerging Sciences Conference (NILES), Giza, Egypt, 28-30 October 2019; Volume 1, pp. 162-165.

53. Srivastava, J.; Bhagat, R.; Kumar, P. Analog inverse filters using OTAs. In Proceedings of the 2020 6th International Conference on Control, Automation and Robotics (ICCAR), Singapore, 20-23 April 2020; pp. 627-631. [CrossRef]

54. Kapoulea, S.; Psychalinos, C.; Elwakil, A.S. Power law filters: A new class of fractional-order filters without a fractional-order Laplacian operator. AEU-Int. J. Electron. Commun. 2021, 129, 153537. [CrossRef]

55. Kapoulea, S.; Psychalinos, C.; Elwakil, A.S.; Tavazoei, M.S. Power-law compensator design for plants with uncertainties: Experimental verification. Electronics 2021, 10, 1305. [CrossRef]

56. Kapoulea, S.; Elwakil, A.S.; Psychalinos, C.; Al-Ali, A. Novel double-dispersion models based on power-law filters. Circuits Syst. Signal Process. 2021, 40, 5799-5812. [CrossRef]

57. Ogata, K. Modern Control Engineering; Prentice Hall: Hoboken, NJ, USA, 2010.

58. Devore, J.L. Probability and Statistics for Engineering and the Sciences; Cengage Learning: Belmont, CA, USA, 2011. 
59. Senani, R.; Bhaskar, D.; Singh, A.K.; Singh, V.K. Current Feedback Operational Amplifiers and Their Applications; Springer: New York, NY, USA, 2013.

60. Mahata, S.; Herencsar, N.; Kubanek, D.; Kar, R.; Mandal, D.; Goknar, C.I. A fractional-order transitional Butterworth-Butterworth filter and its experimental validation. IEEE Access 2021, 9, 129521-129527. [CrossRef] 